\title{
Frontal sinus variation in extant species of the genera Pan, Gorilla and Homo
}

Variation des sinus frontaux chez les espèces actuelles des genres Pan, Gorilla et Homo

Antoine Balzeau, Lou Albessard-Ball, Anna Maria Kubicka, Camille Noûs and Laura T. Buck

\section{(2) OpenEdition}

\section{Journals}

Electronic version

URL: https://journals.openedition.org/bmsap/7840

DOI: $10.4000 /$ bmsap.7840

ISSN: $1777-5469$

Publisher

Société d'Anthropologie de Paris

Electronic reference

Antoine Balzeau, Lou Albessard-Ball, Anna Maria Kubicka, Camille Noûs and Laura T. Buck, "Frontal sinus variation in extant species of the genera Pan, Gorilla and Homo", Bulletins et mémoires de la Société d'Anthropologie de Paris [Online], 33 (2) | 2021, Online since 25 October 2021, connection on 31 October 2021. URL: http://journals.openedition.org/bmsap/7840 ; DOI: https://doi.org/10.4000/ bmsap.7840

\section{(c) (i) (2) $\Theta$}

Les contenus des Bulletins et mémoires de la Société d'Anthropologie de Paris sont mis à disposition selon les termes de la licence Creative Commons Attribution-NonCommercial-NoDerivatives 4.0 International License. 


\title{
Frontal sinus variation in extant species of the genera Pan, Gorilla and Homo
}

\author{
Variation des sinus frontaux chez les espèces actuelles des genres Pan, Gorilla et Homo
}

\author{
Antoine Balzeau (D) 1,2,*, Lou Albessard-Ball (D) ${ }^{3,1}$, Anna Maria Kubicka (1) 4,1, Camille Noûs ${ }^{5}$, Laura T. Buck ${ }^{6}$
}

1 UMR 7194, CNRS, PaleoFED team, Département Homme et Environnement, MNHN, Paris, France

2 Department of African Zoology, Royal Museum for Central Africa, Tervuren, Belgium

3 PalaeoHub, Department of Archaeology, University of York, York, UK

4 Poznań University of Life Sciences, Department of Zoology, Poznań, Poland

5 Cogitamus Laboratory, Nancy, France

6 School of Biological and Environmental Sciences, Liverpool John Moores University, Liverpool, UK

* antoine.balzeau@mnhn.fr

Reçu : 11 mai 2021 ; accepté : 12 septembre 2021 Bulletins et Mémoires de la Société d'Anthropologie de Paris

\begin{abstract}
Frontal pneumatisation is not present in all primates, and among extant species, ethmoidally-derived frontal sinuses are present only in the genera Pan, Gorilla and Homo. A simple and repeatable method is described here to quantify variation in the shape, size and bilateral variation of the frontal sinuses. This has allowed the first large study of these variables, including analyses of large samples of P. paniscus, P. troglodytes, G. gorilla and of several geographically diverse populations of $H$. sapiens. Frontal sinus shape and size are potential phylogenetic markers in primate systematics. We suggest that, in contrast to an allometric relationship between endocranial and frontal sinus form in Pan and Gorilla, H. sapiens is autapomorphic in having highly variable, supero-inferiorly large frontal sinuses, whose size is unrestricted by variation in cranial form. However, we also describe differences in frontal pneumatisation between those taxa. H. sapiens differs from the other taxa in having relatively smaller frontal sinuses that are more variable in shape and size.
\end{abstract}

In P. troglodytes, P. paniscus and G. gorilla, the shape and size of frontal pneumatisation correlates positively with the overall size of the braincase. This suggests that the large space available in the bone structures of the non-human primates analysed allows the sinuses to develop under only slight constraint (if any) from surrounding structures. In $H$. sapiens, a significant correlation is observed between the asymmetry in the anterior extension of the frontal lobes of the brain and the shape and extension of the frontal sinuses. We suggest that the more vertical orientation of the $H$. sapiens frontal bone, its reduced thickness, the reduction of the supraorbital tori and the increased influence of the frontal lobes appear to have modified the integration between the skull, brain and sinuses in the frontal region in our species compared to our nearest extant relatives. Our results reduce the possibility of a strong functional origin for the variation in size and shape of the frontal sinuses in the primates analysed.

Keywords - frontal bone pneumatisation, anatomical integration, brain asymmetries, internal cranial anatomy

Résumé - La pneumatisation frontale n'est pas présente chez tous les primates, et parmi les espèces actuelles, les sinus frontaux d'origine éthmoïdale ne sont présents que dans les genres Pan, Gorilla et chez Homo. Nous avons développé une méthodologie simple et reproductible, quantifiant la variation de la forme, la taille et la variation bilatérale des sinus frontaux. Cela permet la première grande étude de ces variables, y compris des analyses de grands échantillons de P. paniscus, P. troglodytes, G. gorilla et de plusieurs populations géographiquement diverses d'H. sapiens. Nous montrons que la forme et la taille des sinus frontaux sont intéressantes en tant que marqueurs phylogénétiques potentiels dans la systématique des primates. Nous proposons qu'une condition primitive est observée chez $P$. paniscus, $P$. troglodytes et $G$. gorilla par rapport à $H$. sapiens. Cependant, nous décrivons également les spécificités de la pneumatisation frontale entre ces taxons. H. sapiens se distingue des autres espèces actuelles par des sinus frontaux relativement plus petits, de forme et de taille plus variables, avec une extension relative latérale et antéro-postérieure limitée et dont le développement n'est pas lié à la taille du crâne.

Sur la base de ces connaissances uniques, nous explorons les causes et les modalités de l'expression des sinus. Chez P. troglodytes, P. paniscus et G. gorilla, la forme et la taille de la pneumatisation frontale sont positivement corrélés avec la taille globale du crâne. Cela suggère que le grand 
espace disponible dans les structures osseuses des primates non-humains étudiés donne aux sinus la possibilité de se développer d'une manière moins contrainte par les structures environnantes. Au sein de notre propre espèce, la variation observée dans la forme, la disposition et la variation bilatérale de ces structures est beaucoup plus importante que chez les autres espèces étudiées. De plus, chez H. sapiens, une corrélation significative est observée entre le schéma d'asymétrie vers l'avant des lobes frontaux et la forme et l'extension des sinus frontaux. Nous suggérons que l'orientation plus verticale de l'os frontal, son épaisseur réduite, la réduction des superstructures supraorbitaires et l'influence accrue des lobes frontaux ont modifié l'intégration entre le crâne, le cerveau et les sinus dans la région frontale chez notre espèce par rapport aux autres espèces. Nos résultats affaiblissent également la possibilité d'une forte origine fonctionnelle pour la variation de taille et de forme des sinus frontaux chez les espèces de primates étudiées.

Mots clés - pneumatisation de l'os frontal, intégration anatomique, asymétries cérébrales, morphologie interne du crâne

\section{Introduction}

Frontal pneumatisation is not present in all primates: among extant species, ethmoidally-derived frontal sinuses are present only in the genera Pan, Gorilla and Homo (Cave and Haines, 1940; Rae and Koppe, 2004; Rae, 2008). The shape and extent of frontal pneumatisation appear to show a large amount of variation in $H$. sapiens, but these features in other primates have received little attention (but see for example, Blaney, 1986; Rae and Koppe, 2004; Zollikofer et al., 2008), so that their variation is still poorly understood. In addition, while the limited evidence available tends to show that the frontal sinuses are morphologically variable in hominins, which suggests weak selection pressure, they are also used in systematics (Prossinger et al. 2003; Zollikofer et al., 2008; Buck et al., 2019). The study of hominin variation and evolution is not the topic of this paper, but the extensive literature on the topic suggests the need for a better understanding of the variation in (and correlates of) these structures in extant samples of hominines.

Anatomists have been aware of human paranasal sinuses for more than a millennium (Keir, 2009), yet their function (if any) and the correlates of their presence and form are still in debate. This lack of consensus is not due to lack of interest: over the past several hundred years, many colourful explanations have been offered for sinus function (for reviews, see Marquez, 2008; Keir, 2009), from flotation devices (Rhŷs Evans, 1992) to acoustic aids (Howell, 1917) among many others. Three hypotheses that are still widely debated are that sinuses serve to disperse masticatory strain, that they represent climatic adaptation or that they have no function at all (Lund, 1988; Preuschoft et al., 2002; Holton et al., 2013). As there is evidence that the different sinus types (frontal, maxillary, sphenoidal and ethmoidal) may not be functionally and developmentally homologous (Tillier, 1975; Buck et al., 2019), here we discuss these theories of sinus function specifically in the context of frontal sinuses.

It has been suggested that frontal sinuses reduce masticatory strain, with large sinuses explained as adaptations to high-strain diets through the architectural analogy of thin-shelled, curved walls that provide a balance between strength and weight (Bookstein et al., 1999; Wolpoff, 1999; Prossinger et al., 2000; Preuschoft et al., 2002). This explanation has been widely used to interpret the characteristics of fossil hominins (e.g. Bookstein et al., 1999; Seidler et al., 1997). The masticatory strain hypothesis, however, is not well supported for the frontal sinus in primates, as both in vivo and in silico studies show very little masticatory strain in the upper face (Endo, 1965; Ross and Metzger, 2004; Kupczik et al., 2009; Tückmantel et al., 2009; Chalk et al., 2011), making it unlikely that chewing would lead to any adaptation in the frontal bone.

Perhaps the most common explanation for the presence of sinuses is that large sinuses serve to condition inspired air in cold environments (Coon, 1962; Churchill, 1998; Wolpoff, 1999). This theory was developed in particular in the context of the debate about Neandertal anatomy (Rae et al., 2011a; 2011b; Holton et al., 2013). However, frontal sinuses in recent $H$. sapiens are actually smaller in cold environments (Koertvelyessy, 1972; Hanson and Owsley, 1980). Furthermore, it is probable that the ostia (perforations connecting sinuses to the nasal cavity) are too small to allow sufficient gaseous exchange for efficient air conditioning (Negus, 1954; Blaney, 1990).

The evidence against so many theories of sinus function has led to the suggestion that sinuses are functionless evolutionary spandrels (sensu Gould and Lewontin, 1979; e.g. Lund, 1988). In this scenario, sinuses passively expand into available craniofacial space resulting from differential growth in neighbouring craniofacial modules, with differently shaped crania leading to variation in sinus size and shape (Moss and Young, 1960; Blaney, 1990; Vinyard and Smith, 1997; Zollikofer and Weissman, 2008). Such 'spatial' hypotheses are supported by relationships between sinus size and craniofacial variables such as craniofacial size (Lund, 1988; Koppe et al., 1999; Rae, 1999; Rae and Koppe, 2000) and the angle between the face and neurocranium (Seidler et al., 1997; Zollikofer et al., 2008). The large morphological variability of sinuses generally may also be evidence of their lack of function, as functional structures would be expected to be optimised by selection, resulting in greater homogeneity within species (O’Higgins et al., 2006; Buck et al., 2010).

In addition, few scholars have investigated bilateral variation in the expression of the frontal sinuses, yet this may help to explain patterns of sinus development and the correlates of pneumatisation. Moreover, investigations of endocranial casts (reflecting brain shape) reveal that the frontal lobes show frequent, relatively large and clearly lateralised patterns of asymmetry in their anterior disposition and extension, (Balzeau and Gilissen, 2010; Balzeau et al., 2012), which may have some influence on the overlying 
cranial bone and internal features including sinuses. In hominines, the existence of a shared asymmetrical pattern for the petalias - the difference in anterior and lateral extension of the anterior part of the frontal lobe of the brain on one side relative to the other - has been reported (Balzeau and Gilissen, 2010; Balzeau et al., 2012; Neubauer et al., 2020). The degree of asymmetry and the amount of variability distinguish $H$. sapiens from the other extant hominids (Balzeau and Gilissen, 2010; Balzeau et al., 2012; Neubauer et al., 2020). The relationship between these brain asymmetries and bilateral variation in skull anatomy has received little attention (e.g. Heuzé and Balzeau, 2014; Ball-Albessard, 2018), and the possibility of a link with the particularities of frontal pneumatisation has never been studied, although the structures are in close anatomical proximity. Here we investigate the relationship between frontal sinus and endocranial form for the first time.

The complementary objectives of this study allow numerous scientific questions to be addressed about the evolution of frontal pneumatisation and its variation among extant primate species. The first objective is to describe variation in the shape and size of the frontal sinuses among large samples of $P$. paniscus, $P$. troglodytes, G. gorilla and several geographically diverse populations of $H$. sapiens. These are the only extant primate species with ethmoidally-derived frontal sinuses. In this study, a simple and repeatable method for quantifying the sinuses allows the inclusion of a very large sample. Frontal sinuses vary considerably in shape, size, position and extension, which complicates their quantification. The methodology proposed here is crucial for comparisons between the different extant species analysed and for future applications to the hominin fossil record. Patterns of bilateral variation among the samples are also investigated. Patterns of directional and fluctuating asymmetry in sinus dimensions in different orientations are characterised to evaluate potential taxonomic patterns of variation, heritable traits and indicators of developmental instability. Sinus form is also compared with the patterns of frontal petalia to evaluate potential relationships with the shape and asymmetry of the brain. As a result, this first large study of shape and bilateral variation of frontal pneumatisation across extant species of Pan, Gorilla and Homo allows explorations of the causes and modes of expression of the frontal sinuses.

\section{Materials}

A large sample of non-human specimens based on CT imaging was examined. This consisted of 32 P. paniscus, 33 P. troglodytes, and $32 \mathrm{G}$. gorilla from the collections of the Royal Museum of Central Africa (table 1). All were adult wild individuals (Balzeau and Gilissen, 2010). The acquisition parameters varied according to cranial size, and as a result, pixel size and slice thickness ranged from 0.3 to $0.7 \mathrm{~mm}$. Due to specimen availability, there is a skewed representation between sexes with slightly more females than males, which may have some influence on the results. However, this is the largest available sample to date of well-preserved adult specimens from the wild. Moreover, the sex bias is similar between taxa, limiting its influence on the comparative approach.

The $H$. sapiens sample comprises a total of 300 individual crania from different geographic areas (table 1): 78 from Alaska; 48 from Greenland; 71 from the south-east Asia and Pacific region (referred to as 'Pacific' below); 40 from the Oloriz collection in Spain and 63 from a Polish medieval site. Clinical or microCT data for these specimens were obtained from various sources (for details see Copes, 2012; Balzeau et al., 2020). Sex is not known for these samples. Sex was not diagnosed from the skull, as assessment is based on shape and robusticity of the skull, which might also affect sinus form. Postcranial material was not available for the majority of the specimens, further limiting sex determination.

\begin{tabular}{|l|l|c|c|c|c|}
\hline Species & Population & Female & Male & Unknown & Species total \\
\hline Pan paniscus & & 18 & 14 & & $\mathbf{3 2}$ \\
\hline Pan troglodytes & & 19 & 14 & & $\mathbf{3 3}$ \\
\hline Gorilla gorilla & & 19 & 13 & & $\mathbf{3 2}$ \\
\hline
\end{tabular}

\begin{tabular}{|c|c|c|c|}
\hline \multirow{11}{*}{ Homo sapiens } & Alaska & 78 & 300 \\
\hline & Greenland & 48 & \\
\hline & Pacific: New Britain & 6 & \\
\hline & Pacific: Java & 7 & \\
\hline & Pacific: Solomon Islands & 3 & \\
\hline & Pacific: Busuango Island & 1 & \\
\hline & Pacific: Philippines & 1 & \\
\hline & Pacific: New Zealand & 19 & \\
\hline & Pacific: Australia & 34 & \\
\hline & Spain & 40 & \\
\hline & Poland & 63 & \\
\hline
\end{tabular}

Table 1. Samples broken down by species and sex for Pan and Gorilla and by geography for Homo sapiens / Échantillons répartis par espèces et sexe pour les Pan et Gorilla et par la géographie pour Homo sapiens 


\section{Methods}

\section{Measuring frontal sinuses}

$3 \mathrm{D}$ virtual models of the frontal sinuses were reconstructed from the CT scan sets for each individual using manual segmentation with the help of customized settings in Avizo 7 (FEI, Hilsboro, Oregon). Multiple threshold values were necessary, depending on modifications of the grey values of the tissues in the area of frontal pneumatisation: sinuses are sometimes filled with sediment or other materials that need to be removed virtually. The virtual models were then used for qualitative and quantitative analyses. The entire pneumatisation of the frontal sinuses within the frontal superstructures and the squama in 3D was reconstructed and analysed. The inferior extension of the frontal sinuses are not easy to delimit because they are directly connected with the ethmoid pneumatisation (figure 1), with the connecting areas between the frontal and ethmoid sinuses forming the frontal sinus drainage pathway (FSDP), which has no well-defined boundary. Moreover, this area is frequently not preserved in fossil hominins and this aspect has to be considered for future applications of the methodology. As a result, the frontal ostium was used as the inferior limit of the frontal sinuses (Daniels et al., 2003). This has some influence on the resulting volume measurement of pneumatisation that was considered, particularly in Pan and
Gorilla (figure 1), but allows for an easier and more repeatable determination of the extension of the frontal sinuses. Clear specification of the inferior limit used in any study is also necessary for comparison with other work.

The virtual 3D models of the skulls were positioned in the Frankfurt plane. The frontal sinuses were then visualized in anterior, superior and vertical orientations (described below). The pattern for the description of pneumatisation is based on previous work (e.g. Balzeau et al., 2009; Balzeau and Charlier, 2016; Balzeau et al., 2017; Buck et al., 2019) to allow comparisons with these studies.

Metric data were used for two different purposes: to study variation in the $3 \mathrm{D}$ extension of the sinuses among and between samples and to study possible differences in the bilateral extension and proportions of the sinuses. For the quantitative analyses, eight linear dimensions were measured as $2 \mathrm{D}$ projections in three different orientations (figure 2). These measurements define the maximum extension of the frontal sinuses superiorly, inferiorly, laterally, anteriorly and posteriorly, including bilateral data for the two sides of the sinus. Because of the variation observed among extant samples, and for future applications to incomplete hominin fossils, complex quantification including multiple characterizations of smaller details is not possible as it would produce noisy results, without clear information, and would allow only very small samples or would imply a multitude of comparisons for few variables.

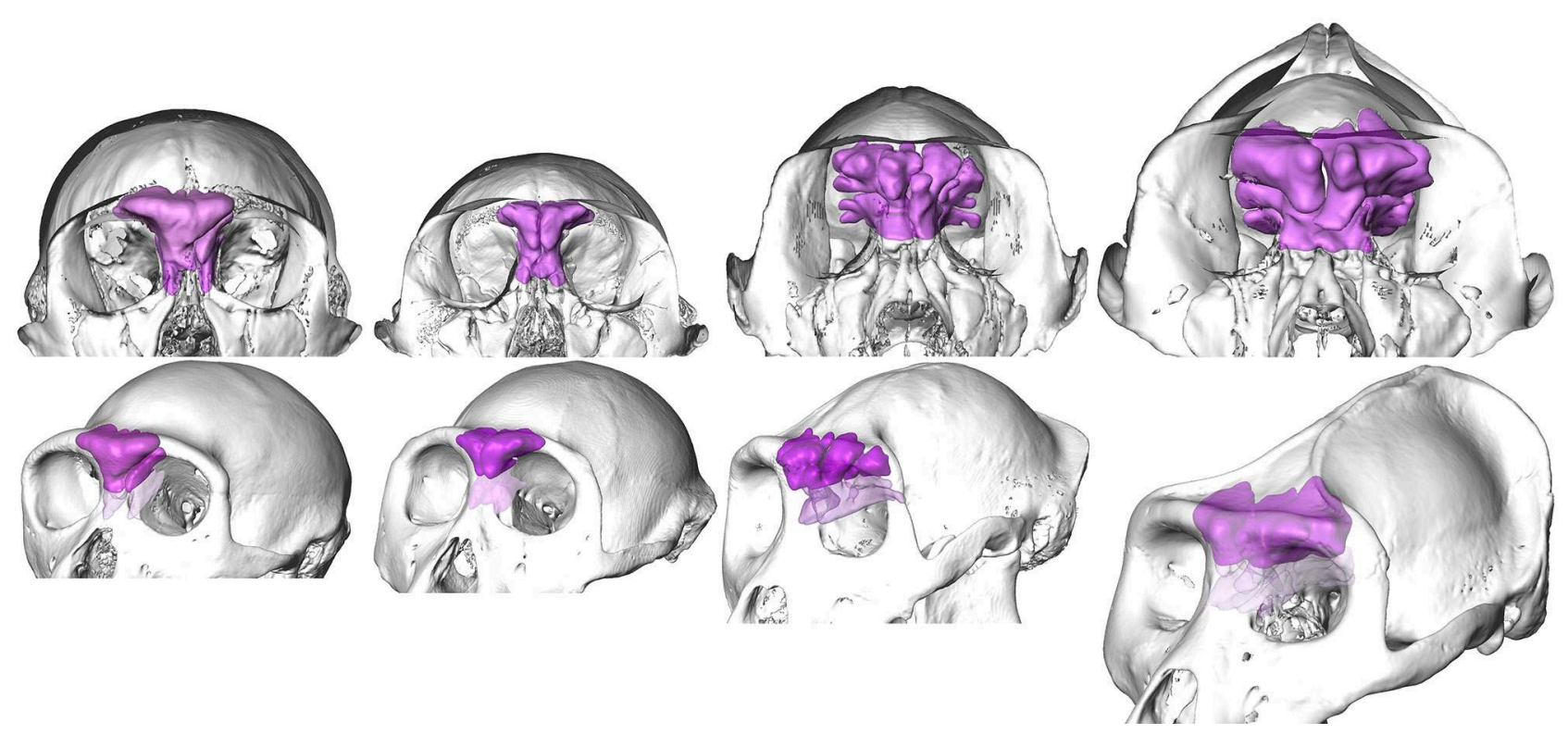

Figure 1. Observation of the position and the extension of pneumatisation of the upper face in specimens of (left to right) Pan paniscus, Pan troglodytes, a Gorilla gorilla female and a Gorilla gorilla male. Upper row: anterior view showing the skull in transparency, in grey, and the extension of ethmoid and frontal pneumatisation shown together in purple. Lower row: $3 / 4$ views of the same skulls showing the extension of the frontal sinuses defined as the pneumatisation located above the level of the frontal ostium (in solid purple) and the ethmoid pneumatisation below (in transparent purple). This definition and inferior extension are used in this paper / Observation de la position et de l'extension de la pneumatisation de la face supérieure chez un spécimen de Pan paniscus (de gauche à droite), Pan troglodytes, une femelle Gorilla gorilla et un Gorilla gorilla mâle. Rangée supérieure : vue antérieure montrant le crâne par transparence, en gris, et l'extension de la pneumatisation de l'ethmoïde et frontale représentées ensemble en violet. Rangée inférieure : vues de 3/4 des mêmes crânes montrant l'extension des sinus frontaux définie comme la pneumatisation située au-dessus du niveau de l'ostium frontal (en violet opaque) et la pneumatisation ethmoïdale en dessous (en violet transparent). Cette définition et cette extension inférieure sont utilisées dans cet article 

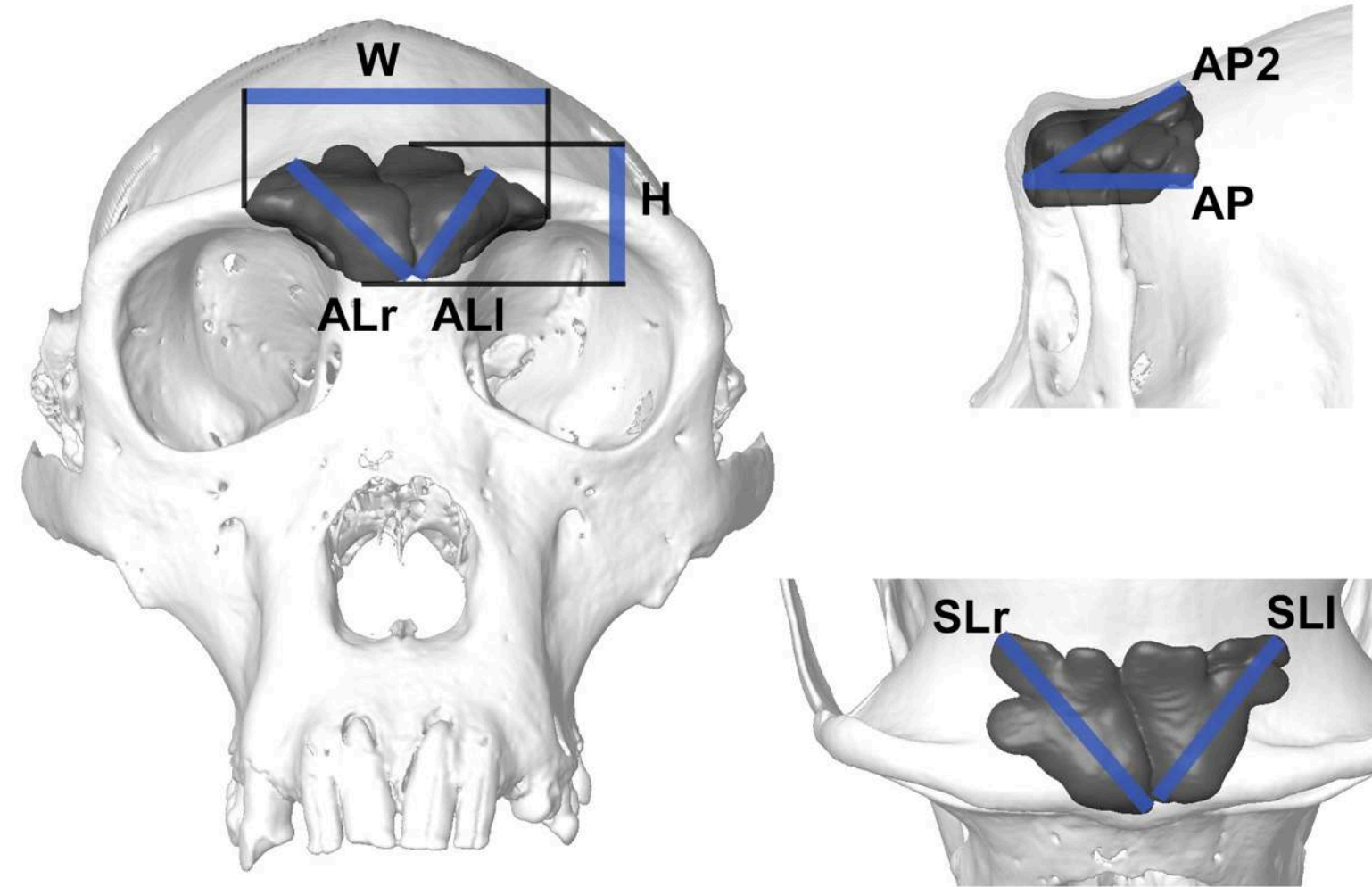

Figure 2. Skull of Pan troglodytes in anterior, lateral and superior views shown using the segmented volume of its frontal sinuses and transparently rendered cranium. Representation of the measurements (table 2) of the extension of the frontal sinuses in different orientations: maximum lateral extension (W), maximum height $(\mathrm{H})$, maximum length of the right and left frontal sinuses (Anterior Length: ALl and ALr) measured from the most medial and inferior point of the sinus to the most distant point of the extension of the sinus measured vertically and laterally in the anterior view; maximum medio-lateral extension of each sinus (Superior Length: SLr and SLI) measured in the superior view; length from the most anteriorly protruding point of the sinus to the most posterior point in a horizontal direction (AP) and length from the most anterior point to the maximum superoposterior extension of the sinuses (AP2) measured in the left lateral view / Le crâne d'un spécimen de Pan troglodytes en vues antérieure, latérale et supérieure illustré en utilisant le volume segmenté de ses sinus frontaux et du crâne rendu transparent. Représentation des mesures (tableau 2) de l'extension des sinus frontaux dans différentes orientations : extension latérale maximale $(W)$, hauteur maximale (H), longueur maximale des sinus frontaux droit et gauche (longueur antérieure : ALl et alr) mesurée du point le plus médial et inférieur du sinus au point le plus éloigné de l'extension du sinus mesuré verticalement et latéralement en vue antérieure ; extension médio-latérale maximale de chaque sinus (longueur supérieure : SLr et SLl) mesurée en vue supérieure ; longueur du point le plus en avant du sinus au point le plus postérieur dans une direction horizontale (AP) et longueur du point le plus antérieur à l'extension supéro-postérieure maximale des sinus (AP2) mesurée en vue latérale gauche

\begin{tabular}{|l|c|l|c|}
\hline Measurement & Abbreviation & Definition & View \\
\hline Width & $\mathrm{W}$ & Maximum lateral extension of pneumatisation & Anterior \\
\hline Height & $\mathrm{H}$ & Maximum supero-inferior height of pneumatisation & Anterior \\
\hline Anterior length, left & $\mathrm{ALl}$ & Maximum infero-medial to supero-lateral length of left sinus & Anterior \\
\hline Anterior length, right & $\mathrm{ALr}$ & Maximum infero-medial to supero-lateral length of right sinus & Anterior \\
\hline Anterior length & $2 \mathrm{Al}$ & $\mathrm{ALr}+\mathrm{ALl}$ & Anterior \\
\hline Superior length, left & $\mathrm{SLl}$ & Maximum medio-lateral extension of left sinus & Superior \\
\hline Superior length, right & $\mathrm{SLr}$ & Maximum medio-lateral extension of right sinus & Superior \\
\hline Superior length & 2S1 & SLr + SLl & Superior \\
\hline Anterior projection & $\mathrm{AP}$ & Anteroposterior length & Left lateral \\
\hline \multirow{2}{*}{ Anterior projection 2 } & AP2 & Most anterior point to most supero-posterior point & Left lateral \\
\cline { 2 - 4 } & 2AP & AP + AP2 & Left lateral \\
\hline
\end{tabular}

Table 2. Linear measurements taken of frontal sinuses / Mesures linéaires quantifiées sur les sinus frontaux 
The selected distances (figure 2, table 2) measured in the anterior view are the maximal mediolateral width $(\mathrm{W})$, superoinferior height $(\mathrm{H})$ and the maximal anterior length of the right and left frontal sinuses (Anterior Length: ALl and ALr), where the anterior length was measured from the most medial and inferior point of the sinus to the most distant point of the extension of the sinus vertically and laterally. In the superior view, the maximal mediolateral extension of each sinus (Superior Length: SLr and SLl) was measured. In the left lateral view, the length from the most anteriorly protruding point of the sinus to the most posterior point in a horizontal direction (AP) and the length from the most anterior point to the maximal superoposterior extension of the sinuses (AP2) were measured. The volume of the frontal sinuses was also measured. These variables were selected because they are not significantly affected by sinus preservation. The inferior extension of the sinuses tends to be less well preserved than the rest of the sinus; only specimens that were sufficiently well preserved for a precise characterisation of the dimensions were measured.

Detailed statistics for all the quantified parameters in this paper are given below. The raw morphometric information on individual values for all variables is available on request from the first author.

\section{Morphometric comparisons}

Comparisons between samples of the extension of pneumatisation concerned variables $\mathrm{W}$ and $\mathrm{H}$, as well as the lateral extension of the sinus in the anterior and superior views and the anteroposterior lengths of the sinuses. The lateral extensions were measured separately on the left and right side for bilateral comparisons. For the comparative analyses, the two bilateral measurements were combined together; the maximal length of the two sinuses in the anterior and superior views are labelled 2AL (corresponding to $\mathrm{ALr}+\mathrm{ALl}$ ) and 2SL (corresponding to SLr $+\mathrm{SLl}$ ). The two anteroposterior dimensions were also combined as a single variable, defined as $2 \mathrm{AP}$, by addition of the two measurements (AP and AP2). The raw data for these five variables (W, H, 2AL, 2SL, 2AP) were compared in three dimensions. Sinus volume is reported as the cube root of the volume of pneumatisation (denoted RCV). Cube root values are used instead of volume for two reasons. The first is that it is in comparable dimensions to the other variables (moreover, the incomplete preservation of the sinuses may have the most influence on volume of all the variables analysed). Using cube roots allowed us to minimize the magnitude of any potential measurement error. Finally, this variable was used for trait size correction for subsequent analyses. The resulting relative data set analysed corresponds to the variables labelled Wr, Hr, 2ALr, 2SLr and 2Apr. The calculated size-corrected dimensions were also used to compare variation in the shape of pneumatisation between the samples. The resulting dataset was subjected to multivariate analyses, including PCA (with the variancecovariance matrix) and discriminant analyses. PCA is an unsupervised method that plots specimens independently of their group of origin. It can be informative to observe the relationships between variables. Discriminant analyses are useful to produce the maximum separation between groups along two axes and to evaluate levels of classification accuracy a posteriori. These two complementary methods were chosen to maximise the information extracted from the dataset.

The coefficient of variation $(\mathrm{CV}=\mathrm{SD} /$ mean $)$, corrected for small sample size using the $\mathrm{V}^{*}$ parameter, calculated as $[(1+1 / 4 \mathrm{~N}) \times \mathrm{CV}]$ and expressed in percentages (Sokal and Braumann, 1980; Wood and Lieberman, 2001), was used to compare the extent of variation between samples.

All the statistical procedures were conducted in Past ver. 4.02 (Hammer et al., 2001). Linear regressions were calculated with the Reduced Major Axis method (Miller and Kahn, 1962), which handles errors in both variables (Smith, 2009). Histograms showing density and kernel curves were computed in R (R Core Team, 2014). Density is displayed rather than frequency because it can be plotted on the same scale as the kernel curve. Boxplots were also computed in $\mathrm{R}$, showing the median, the inter-quartile range and the sample range, with all data points plotted on top as individual points.

\section{Bilateral variation and asymmetry}

A second approach was used to investigate variations between species in the extension of the sinuses, including bilateral variation. The large sample used in this study allowed comparisons of departures from symmetry for the frontal sinuses. Fluctuating asymmetry (FA) refers to small, random deviations away from perfect bilateral symmetry and is related to developmental instability (DI) (Palmer, 1994). Directional asymmetry (DA) is a pattern of bilateral variation in a sample when one side is consistently larger than the other side (Palmer, 1994). Patterns in both directional and fluctuating asymmetry in lengths in the anterior (ALl and ALr) and superior (SLl and SLr) views were analysed to evaluate specific variation, heritable traits and indicators of DI. FA and DI are influenced by trait size, from which they are quantified. The size correction using the cube root of sinus volume was therefore used for comparisons of the degree and extent of bilateral variation of the frontal sinuses.

Analyses of FA are complex and may be strongly influenced by measurement error and sample error, as FA always represents a small part of trait size (Palmer, 1994). A sample of 30 specimens was measured twice to test the validity of the measurements. During this test, repeatability was high, as variation between the repetitions of the measurements was well below a millimetre and comparable to the resolution of the imaging data. Moreover, to provide better repeatability in the methodology, simple linear distances were used to quantify dimensions of the sinuses, which may vary substantially in shape. This protocol for the morphometric quantification of the sinuses and study of their bilateral 
variation is similar to those used to quantify the petalias of the brain (Balzeau and Gilissen, 2010; Balzeau et al., 2011). The complete morphometric dataset was carefully checked for sampling errors through visual inspection of calculated distances and examination of their variation within and between samples. Grubbs' test statistic (Grubbs, 1969) was used to recognize statistically significant outliers (which have more effect on the variance than on the mean). Significant outliers were excluded from analyses of FA, even if the values were related to normal variation and were not measurement errors, so as not to bias the detection of patterns of symmetry. Shapiro-Wilk tests were used to determine whether the variables followed a Gaussian distribution.

Conventional FA indices (Palmer, 1994; Palmer and Strobeck, 2003) were used in the analysis of frontal sinus variation (table 3 ). Signed asymmetry is the difference between the right (R) and left (L) sides for each trait in an individual (R-L). This parameter informs about the direction of the asymmetry to one side or the other. FA1 and FA2 are indicators of global estimation of the absolute and relative bilateral differences. FA1 is the mean $|\mathrm{R}-\mathrm{L}|$. FA2 is calculated using the formula FA2 = mean $[|\mathrm{R}-\mathrm{L}| /((\mathrm{R}+\mathrm{L}) / 2)]$. FA4a is a corrected factor of the variation in mean asymmetry. It is calculated using the formula FA4a $=0.798 \sqrt{ }$ var (R-L). DA is therefore identified by statistical tests for departures of the mean (R-L) from zero (Van Valen, 1962). Anti-symmetry is a pattern of bilateral variation in a sample where a significant difference exists between both sides, but where the larger side varies randomly among individuals (Palmer, 1994). Mean (R-L) (also named DA) and FA4a were compared. When DA $\leq$ FA4a, the predisposition towards one side is less than the average deviation around the mean (R-L) (Palmer and Strobeck, 2003). In those cases, deviations from the mean DA may be principally related to developmental instability (DI). Values for kurtosis were compared to tables of critical values for platy- and leptokurtosis (Palmer and Strobeck, 2003, table 5, values for Equation (7)). The procedures to test for skewness and the corresponding tables for critical values are detailed in Sokal and Rohlf (1995). A sequential Bonferroni procedure was used for post-hoc multiple test correction for all statistical procedures (Rice, 1989; Palmer, 1999).

Additionally, the pattern of bilateral variation in the dimensions of the frontal sinuses and the bilateral variation in the extension of the frontal lobe in Pan, Gorilla and H. sapiens were compared. To do so, a previously established protocol to quantify the relative position of the frontal poles was used. The frontal poles are the most anterior point on each of the frontal lobes. Data for the petalias were extracted from previous publications for the Pan and Gorilla samples (Balzeau and Gilissen, 2010), for the Spanish human sample (Balzeau et al., 2011) and for part of the human sample from Poland (Balzeau et al., 2020). R-L frontal petalias were characterised qualitatively as described by Holloway and de la Coste-Lareymondie (1982), taking into consideration the lateral extension of the anterior part of the frontal lobes in the superior view.

The concept of statistical significance is problematic (Amrhein et al., 2019). However, complex concepts (FA, DA, DI, etc.) concerning anatomical traits with various degrees and patterns of departure from bilateral symmetry are analysed here. Well-established methodologies to study symmetry were followed here and statistical procedures (Palmer, 1994; Palmer and Strobeck, 2003) adapted to study bilateral variation were used. Following the suggestion of Amrhein et al. (2019), significance thresholds were not used alone, but the whole meaning of the results was explored, including seemingly "non-significant" or "negative" results. Such a complete descriptive approach is the norm for a detailed and precise study of departure from symmetry (e.g. Palmer and Strobeck, 2003; Balzeau et al., 2020).

\begin{tabular}{|l|l|l|}
\hline FA indices & Definition & Calculation \\
\hline Signed asymmetry & $\begin{array}{l}\text { Difference between right and left measurements } \\
\text { of a trait in an individual }\end{array}$ & R-L \\
\hline FA1 & Mean absolute asymmetry for the sample & mean $|\mathrm{R}-\mathrm{L}|$ \\
\hline FA2 & $\begin{array}{l}\text { Mean absolute asymmetry divided by trait side } \\
\text { for the complete sample }\end{array}$ & mean $[|\mathrm{R}-\mathrm{L}| /((\mathrm{R}+\mathrm{L}) / 2)]$ \\
\hline FA4a & Corrected factor of the variation in mean asymmetry & $0.798 V_{\text {var }(\mathrm{R}-\mathrm{L})}$ \\
\hline Directional asymmetry (DA) & $\begin{array}{l}\text { Pattern of bilateral variation in sample } \\
\text { where one side is statistically larger }\end{array}$ & $\begin{array}{l}\text { Departure of mean }(\mathrm{R}-\mathrm{L}) \\
\text { from zero }\end{array}$ \\
\hline Antisymmetry & $\begin{array}{l}\text { Pattern of bilateral variation in sample } \\
\text { where larger side varies randomly between specimens }\end{array}$ & \\
\hline
\end{tabular}

Table 3. FA indices used to assess asymmetry in frontal sinus measurements / Indices d'analyse des asymétries utilisés sur les mesures des sinus frontaux 


\section{Results}

\section{Does sinus size matter?}

All the specimens of $P$. paniscus, $P$. troglodytes and $G$. gorilla examined have frontal sinuses. In one bonobo and one chimpanzee (samples 32 and 33 respectively), pneumatisation comprises only the right sinus. In the sample of 300 H. sapiens, 38 (12.7\%) have no sinus, 23 (7.7\%) only a left sinus, and $9(3 \%)$ only a right sinus. When only one sinus is present, this is always accompanied by the appearance of restricted development of pneumatisation on the contralateral side. In those cases, there is no propagation of the ethmoid pneumatisation vertically on the non-pneumatised side. Moreover, no continuous pneumatisation between the left and right sinuses was observed in the samples analysed, which is in contrast to the frontal sinus form of some extinct hominin fossils (e.g. Zollikofer et al., 2008; Balzeau et al., 2017; Buck et al., 2019).

Mean values for the raw volume of the sinuses in the nonhuman taxa (table 4) are larger in males than in females in P. troglodytes (respectively $5.76 \mathrm{~cm}^{3}$ and $4.79 \mathrm{~cm}^{3}, \mathrm{t}=1.15$, $\mathrm{p}=0.26$ ) and $G$. gorilla (respectively $20.92 \mathrm{~cm}^{3}$ and $\left.10.49 \mathrm{~cm}^{3}, \mathrm{t}=4, \mathrm{p}=0.0001\right)$. The mean volume is larger in females in P. paniscus $\left(2.63 \mathrm{~cm}^{3}\right.$ compared to $1.74 \mathrm{~cm}^{3}$ in males, $\mathrm{t}=1.5, \mathrm{p}=0.14)$, although this difference does not reach significance. The mean value for endocranial volume is always larger in males in $P$. paniscus (respectively $355.6 \mathrm{~cm}^{3}$ and $333.8 \mathrm{~cm}^{3}, \mathrm{t}=0.99, \mathrm{p}=0.34$ ), P. troglodytes (respectively $416.6 \mathrm{~cm}^{3}$ and $363.4 \mathrm{~cm}^{3}, \mathrm{t}=5.2, \mathrm{p}=0.0001$ ) and $G$. gorilla (respectively 538.0 and $452.0 \mathrm{~cm}^{3}, \mathrm{t}=5.2$, $\mathrm{p}=0.0001$ ). Sexual dimorphism in absolute values is small in $P$. paniscus, larger in $P$. troglodytes and even larger in $G$. gorilla for both frontal sinus and endocranial sizes. When the whole non-human sample is considered (figure 3), there is a significant correlation between the cube roots of the frontal sinus volume and the endocranial volume (slope $=$ $0.74, \mathrm{r}=0.72, \mathrm{p}=10 \mathrm{e}-16$; and after $\log$-log transformation, slope $=0.16, \mathrm{r}=0.65, \mathrm{p}=10 \mathrm{e}-12)$. The observed larger mean value for the volume of the frontal sinuses in females compared to males in P. paniscus may be related to several parameters such as smaller absolute dimensions, larger variation and reduced sexual dimorphism compared to the other Pan and Gorilla samples, as well as the relatively small sample sizes. In any case, the relationship between frontal sinus and endocranial sizes remains positive but with different parameters within the different samples of $P$. paniscus (slope $=1.33, \mathrm{r}=0.11, \mathrm{p}=0.56)$, P. troglodytes (slope $=1.27, \mathrm{r}=0.18, \mathrm{p}=0.3)$ and $G$. gorilla $($ slope $=1.16$, $\mathrm{r}=0.45, \mathrm{p}=0.009)$. The correlation remains significant only in G. gorilla.

There is no significant relationship between the volume of the frontal sinuses and the endocranial volume in the Spanish human sample for which endocranial volumes were available ( slope $=1.39, \mathrm{r}=0.11, \mathrm{p}=0.51$ ). The positive relationship and the statistical parameters for this sample are similar to those that obtain in P. paniscus and P. troglodytes. However, $H$. sapiens has smaller pneumatisation volumes compared to the other taxa studied here, and much larger endocranial volumes when the whole analysed sample is considered. For this reason, H. sapiens does not follow the general trend of a relationship between frontal sinus and endocranial sizes as observed in the whole Pan and Gorilla samples.

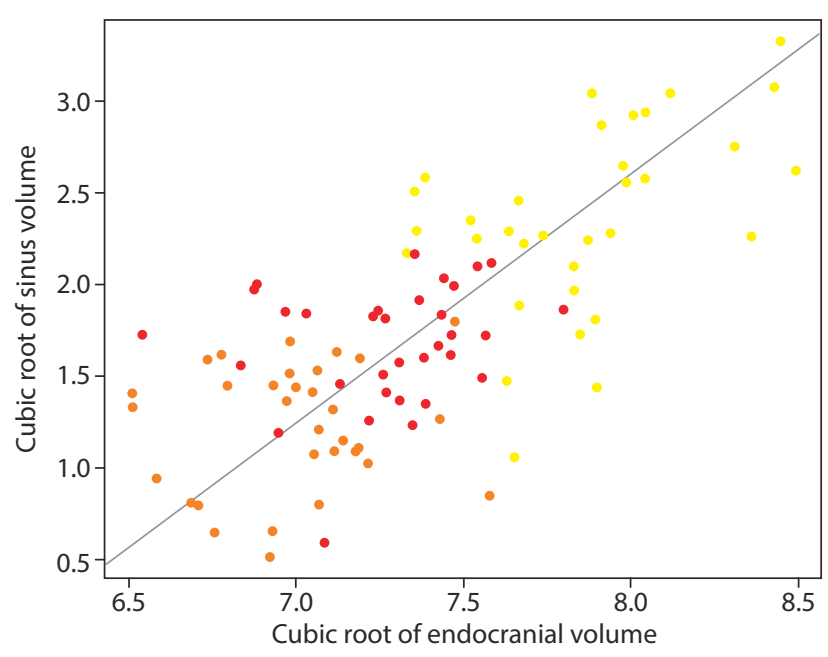

Figure 3. Regression of the cube root of the volume of the frontal sinuses relative to the cube root of the endocranial volume (both in $\mathrm{mm}$ ) in Pan and Gorilla; orange dots: Pan paniscus, red dots: Pan troglodytes, yellow dots: Gorilla gorilla / Régression de la racine cubique du volume des sinus frontaux par rapport à la racine cubique du volume endocrânien, les deux sont en $\mathrm{mm}$, chez Pan et Gorilla; points orange : Pan paniscus, points rouges : Pan troglodytes, points jaunes : Gorilla gorilla

\begin{tabular}{|l|c|c|c|c|}
\hline \multirow{2}{*}{ Species } & \multicolumn{2}{|c|}{ Frontal sinus volume } & \multicolumn{2}{c|}{ Endocranial volume } \\
\cline { 2 - 5 } & Female & Male & Female & Male \\
\hline Pan paniscus & 2.63 & 1.74 & 333.80 & 355.6 \\
\hline Pan troglodytes & 4.79 & 5.76 & 363.40 & 416.6 \\
\hline Gorilla gorilla & 10.49 & 20.92 & 452.00 & 538.0 \\
\hline
\end{tabular}

Table 4. Mean sinus and endocranial volumes for Pan and Gorilla. All measurements are in $\mathrm{cm}^{3}$ / Valeurs moyennes pour le volume des sinus frontaux et pour le volume endocrânien chez les Pan et Gorilla. Toutes les mesures sont en $\mathrm{cm}^{3}$ 


\section{Morphometric comparison}

There are clear differences between the samples in the position and extension of pneumatisation (table 5, figure 4). Gorillas have the largest pneumatisation in terms of volume and size in all directions when absolute values are considered. The values are lower in chimpanzees and even more so in bonobos. This variation among non-human hominines is likely to be allometric. The $H$. sapiens sample has mean values that are close to those observed in bonobos, but with some differences in terms of relative distribution. Variation (expressed in table 5 by the parameter $\mathrm{V}^{*}$ ) is smaller for all variables in gorillas, larger in chimpanzees and even larger in bonobos. The mean for the raw data for $\mathrm{V}^{*}$ is 23.3 in gorillas, 26.9 in chimpanzees and 37.3 in bonobos. The observed variation for $H$. sapiens is far larger (mean $\mathrm{V}^{*}=65.6$ ), showing the considerable differences observed between non-pneumatised specimens and those with pneumatisation as large as that observed in the more pneumatised Pan and Gorilla samples. This cannot be due solely to the much larger sample of $H$. sapiens, as a coefficient of variation that takes small sample size into account was used (Sokal and Braumann, 1980; Wood and Lieberman, 2001).

In terms of relative dimensions, gorillas are remarkable among the samples analysed for the lateral and anteroposterior extension of their pneumatisation, as expressed in particular by the large values observed for 2SLr and $2 \mathrm{Apr}$ (table 5). The pattern of distribution shows some differences between bonobos and chimpanzees, with chimpanzees having relatively higher values for $2 \operatorname{SLr}(\mathrm{t}=1.7, \mathrm{p}=0.09)$ and $2 \operatorname{Apr}(\mathrm{t}=1.6, \mathrm{p}=0.11)$. H. sapiens has proportions that are closer to bonobos than to chimpanzees and gorillas, but with much lower values for 2 SLr and $2 \mathrm{Apr}$. The values and variation for relative height and width differentiate the different samples of Pan and Gorilla less clearly (figure 5). $H$. sapiens differs from the other samples in the larger values for relative height and lower values for $2 \mathrm{SLr}$ and $2 \mathrm{Alr}$, respectively a lateral and a vertical dimension. Interestingly, the pattern observed for the lateral extension of the frontal sinuses is different for $H$. sapiens relatively to the other samples in the two orientations analysed. H. sapiens has values for 2 Alr similar to those of the other taxa, but lower values for $2 \mathrm{SLr}$. This is related to the shape of the frontal sinuses in $H$. sapiens, which are particularly extended in the vertical direction, as indicated by their high values for relative height. The maximal extension of the sinuses in the anterior view (2Alr) includes a vertical and a lateral component, which explains the relatively high values in $H$. sapiens. In contrast, the dimension in the superior view, 2SLr, is smaller for $H$. sapiens. The more globular shape of the sinuses in Pan and Gorilla accounts for the higher values for 2 Apr. As a result, a clear discrimination exists between those samples, related first to size (table 5, figure 4), but also to shape (figure 5), particularly in the anteroposterior and lateral directions that discriminate gorillas and in the vertical direction that discriminates $H$. sapiens.

\begin{tabular}{|c|c|c|c|c|c|c|c|c|c|c|c|}
\cline { 2 - 12 } \multicolumn{1}{c|}{} & W & H & 2AL & 2SL & 2AP & RC V & Wr & Hr & 2ALr & 2SLr & 2APr \\
\cline { 2 - 12 } & \multicolumn{10}{c|}{ Pan paniscus $(\mathrm{N}=32)$} \\
\hline Mean & $\mathbf{3 0 . 7}$ & $\mathbf{1 5 . 7}$ & $\mathbf{3 2 . 7}$ & $\mathbf{3 5 . 4}$ & $\mathbf{2 8 . 3}$ & $\mathbf{1 2 . 2}$ & $\mathbf{2 4 4 . 8}$ & $\mathbf{1 2 9 . 6}$ & $\mathbf{2 6 3 . 7}$ & $\mathbf{2 8 1 . 5}$ & $\mathbf{2 2 6 . 1}$ \\
\hline $\mathrm{V}^{*}$ & 41.3 & 33.1 & 39.4 & 41.6 & 40.1 & 28.2 & 21.7 & 23.9 & 21.1 & 20.9 & 22.8 \\
\hline
\end{tabular}

\begin{tabular}{|c|c|c|c|c|c|c|c|c|c|c|c|}
\cline { 2 - 11 } \multicolumn{1}{c|}{} & \multicolumn{10}{c|}{ Pan troglodytes $(\mathrm{N}=33)$} \\
\hline Mean & $\mathbf{4 0 . 8}$ & $\mathbf{1 8 . 4}$ & $\mathbf{4 3 . 1}$ & $\mathbf{5 1 . 7}$ & $\mathbf{4 1 . 3}$ & $\mathbf{1 6 . 8}$ & $\mathbf{2 4 1 . 3}$ & $\mathbf{1 1 0 . 3}$ & $\mathbf{2 5 8 . 0}$ & $\mathbf{3 0 3 . 5}$ & $\mathbf{2 4 3 . 8}$ \\
\hline $\mathrm{V}^{*}$ & 27.4 & 24.3 & 22.7 & 30.2 & 30.1 & 19.8 & 12.8 & 18.1 & 13.5 & 15.2 & 15.3 \\
\hline
\end{tabular}

\begin{tabular}{|c|c|c|c|c|c|c|c|c|c|c|c|}
\cline { 2 - 11 } \multicolumn{1}{c|}{} & \multicolumn{10}{c|}{ Gorilla gorilla $(\mathrm{N}=33)$} \\
\hline Mean & $\mathbf{6 4 . 9}$ & $\mathbf{2 4 . 1}$ & $\mathbf{6 1 . 1}$ & $\mathbf{8 1 . 5}$ & $\mathbf{7 3 . 2}$ & $\mathbf{2 3 . 7}$ & $\mathbf{2 7 5 . 8}$ & $\mathbf{1 0 1 . 7}$ & $\mathbf{2 5 9 . 2}$ & $\mathbf{3 4 4 . 2}$ & $\mathbf{3 0 7 . 7}$ \\
\hline $\mathrm{V}^{*}$ & 20.8 & 26.0 & 21.5 & 23.8 & 26.1 & 21.8 & 9.6 & 13.6 & 11.2 & 14.4 & 11.8 \\
\hline
\end{tabular}

\begin{tabular}{|c|c|c|c|c|c|c|c|c|c|c|c|}
\cline { 2 - 13 } \multicolumn{1}{c|}{} & \multicolumn{10}{c|}{ Homo sapiens $(\mathrm{N}=300)$} \\
\hline Mean & $\mathbf{3 1 . 4}$ & $\mathbf{1 7 . 6}$ & $\mathbf{3 2 . 0}$ & $\mathbf{3 0 . 4}$ & $\mathbf{1 9 . 1}$ & $\mathbf{1 1 . 1}$ & $\mathbf{2 4 5 . 5}$ & $\mathbf{1 3 6 . 4}$ & $\mathbf{2 4 1 . 7}$ & $\mathbf{2 2 3 . 5}$ & $\mathbf{1 4 4 . 5}$ \\
\hline $\mathrm{V}^{*}$ & 61.9 & 62.8 & 66.2 & 71.8 & 71.7 & 59.3 & 49.4 & 44.2 & 45.8 & 47.6 & 46.1 \\
\hline
\end{tabular}

Table 5. Morphometric data (in mm for W, H, 2AL, 2SL, 2AP and RCV; the cube root of the volume of pneumatisation was used for trait size correction) for pneumatisation of the frontal bone among Pan and Gorilla samples / Données morphométriques (en mm pour W, H, 2AL, 2SL, 2AP et RCV; la racine cubique du volume de la pneumatisation a été utilisée pour la correction de la taille des traits) pour la pneumatisation de l'os frontal parmi les échantillons Pan et Gorilla 


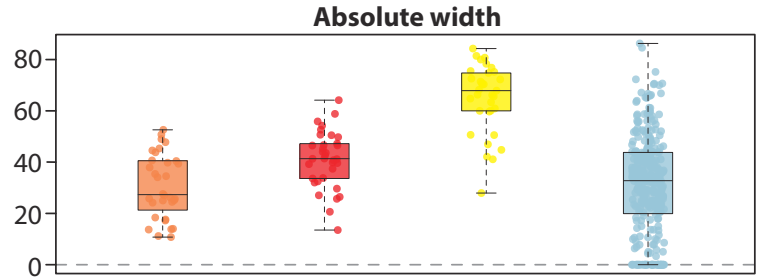

2AL

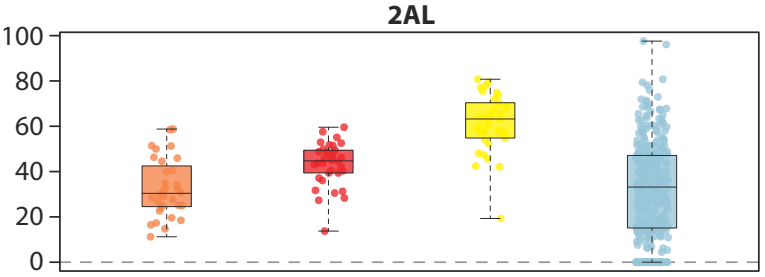

2AP

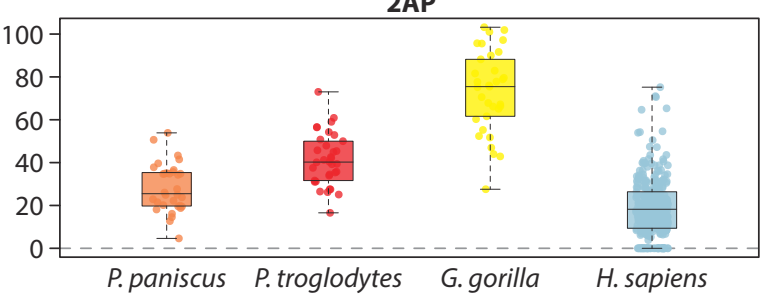

Absolute height

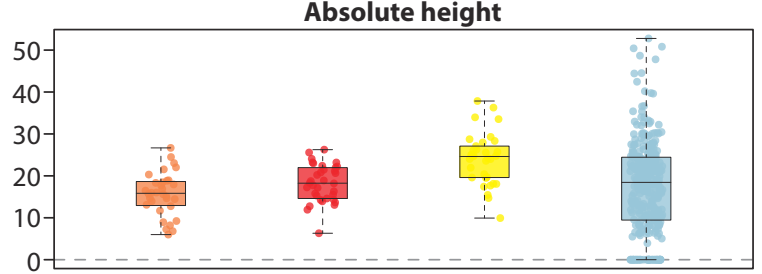

2SL

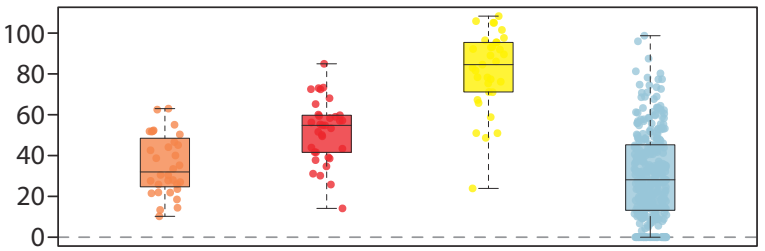

RCV

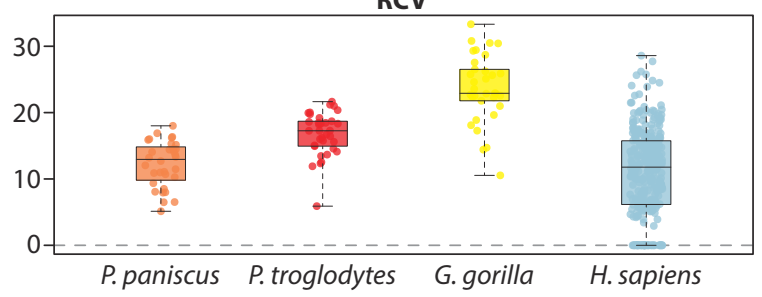

Figure 4. Absolute values for the different dimensions (in mm; width, height, 2AL: R+L anterior length, 2SL: R+L superior length, 2AP: combined antero-posterior dimensions and RCV: cube root of the volume of the frontal sinuses) of frontal pneumatisation in Pan, Gorilla and Homo sapiens / Valeurs absolues des différentes dimensions (en mm; largeur, hauteur, 2AL: longueur antérieure $R+L, 2 S L$ : longueur supérieure $R+L, 2 A P$ : dimensions antéro-postérieures combinées et $R C V$ : racine cubique du volume des sinus frontaux) de la pneumatisation frontale chez Pan, Gorilla et Homo sapiens

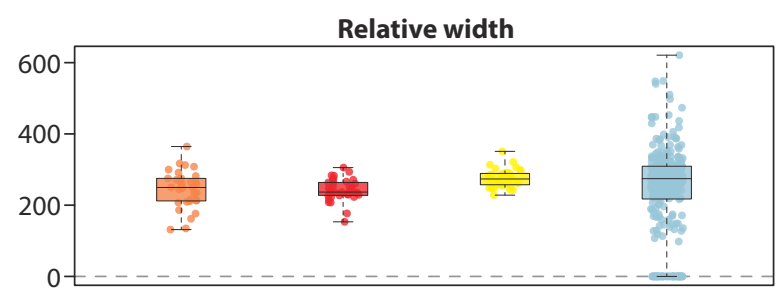

2ALr

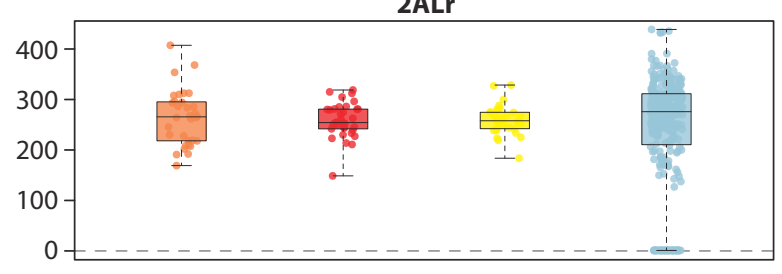

2APr

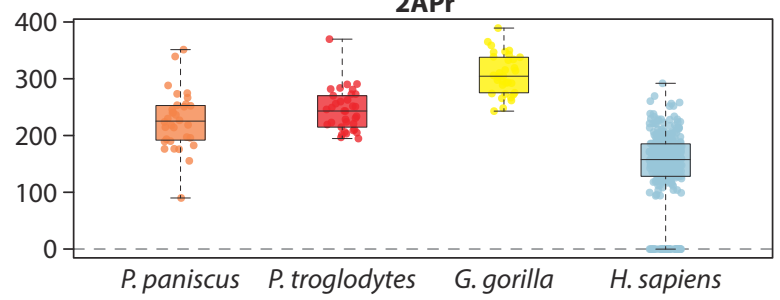

Figure 5. Relative values for the different dimensions (relative width, relative height, 2ALr: R+L anterior length, 2SLr: R+L superior length and 2APr: combined antero-posterior dimensions; the cube root of the volume of pneumatisation was used for trait size correction) of frontal pneumatisation in Pan, Gorilla and Homo sapiens / Valeurs relatives pour les différentes dimensions (largeur relative, hauteur relative, $2 A L r$ : longueur antérieure $R+L, 2 S L r$ : longueur supérieure $R+L$ et $2 A P r$ : dimensions antéropostérieures combinées ; la racine cubique du volume de la pneumatisation a été utilisée pour correction de la taille du trait) de la pneumatisation frontale chez Pan, Gorilla et Homo sapiens
Relative height
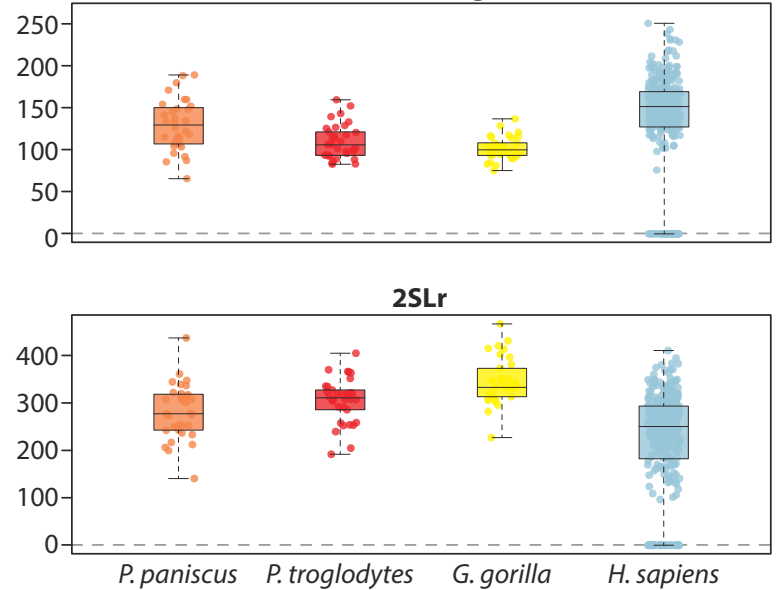


\section{Multivariate comparisons}

The PCA computed for all the raw data variables illustrates the strong influence of size (figure 6). PC1-2 represent $90.46 \%$ and $6.35 \%$ of the variance respectively, and all variables have high positive loadings on the first axis. This analysis also separates $H$. sapiens from the other taxa due to the low values for the $2 \mathrm{AP}$ and $2 \mathrm{SL}$ variables in $H$. sapiens.
These results are interesting from the perspective of the ongoing study of the variation observed in these features among different species in the hominin fossil record, as some clear distinctions appear between different living species. A discriminant analysis computed with relative data discriminates well between $H$. sapiens and Pan and Gorilla (figure 6). The distribution of the bonobos overlaps with the three other taxa in both analyses.
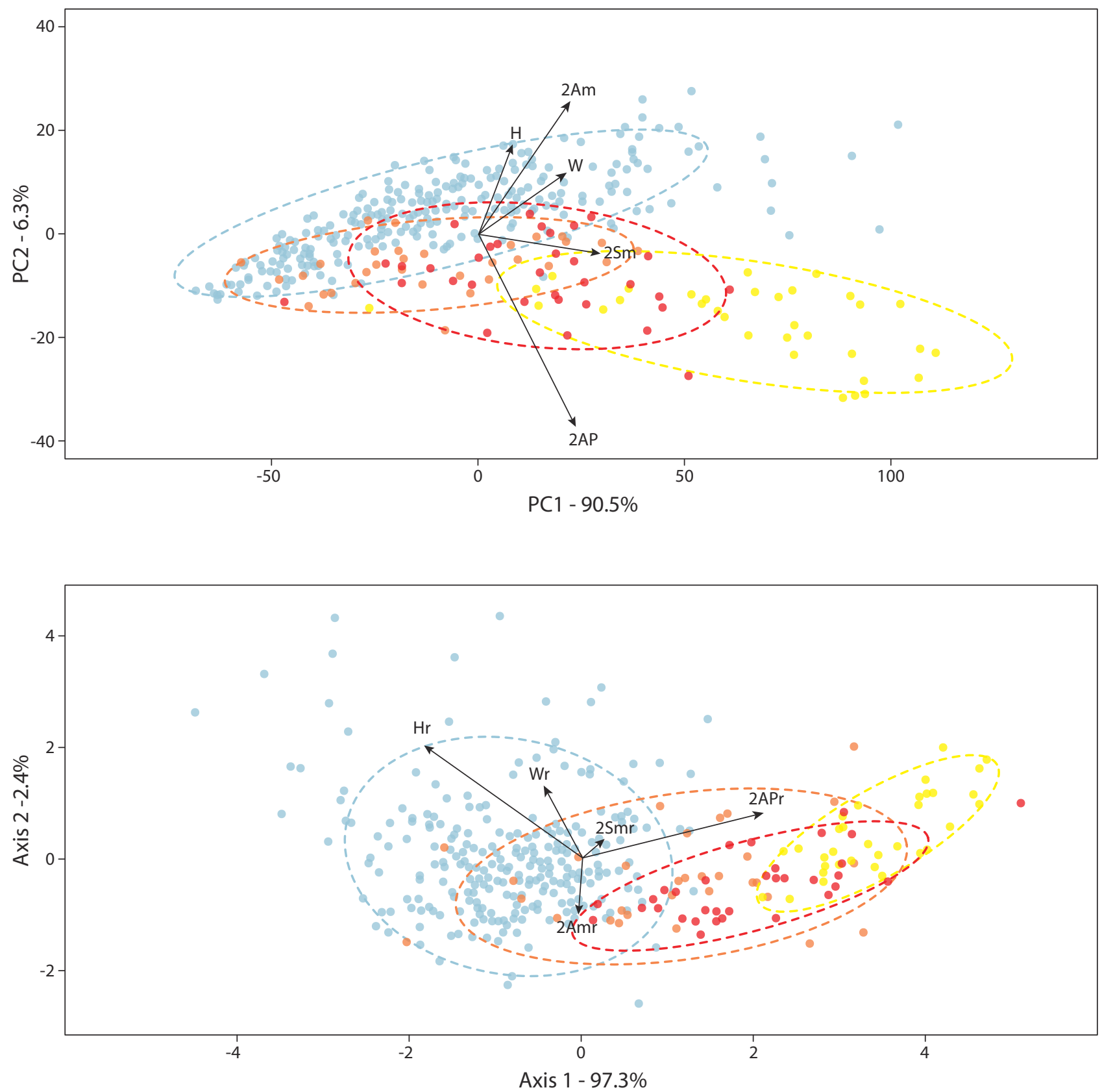

Figure 6. Multivariate analyses (left: PCA of absolute values; right: DA of relative values) of the measurements of frontal pneumatisation in all directions in extant samples. The colour grouping for species is the same for both analyses; orange dots: Pan paniscus, red dots: Pan troglodytes, yellow dots: Gorilla gorilla, blue dots: Homo sapiens) / Analyses multivariées (à gauche: ACP des valeurs absolues et à droite : AD des valeurs relatives) des mesures de pneumatisation frontale dans toutes les directions dans les échantillons actuels. Le regroupement des couleurs pour les espèces est le même pour les deux analyses; points orange : Pan paniscus, points rouges : Pan troglodytes, points jaunes : Gorilla gorilla, points bleus : Homo sapiens) 
Intraspecific variation in frontal sinus morphology in Homo sapiens

There is a certain degree of variation between the different samples of $H$. sapiens (table 6). Variation (as quantified by the parameter $\mathrm{V}^{*}$ ) in pneumatisation is larger in the samples from Alaska, Greenland and the Pacific region compared to the two European samples, while the latter have larger absolute dimensions. The samples from Alaska, Greenland and the Pacific region have more non-pneumatised individuals than the European samples. The European samples share similar values for the different dimensions of the sinuses. Similarly, the Alaska and Greenland samples share similar values.
Relative dimensions separate out the different samples less well than absolute dimensions. One-way analysis of similarities (ANOSIM) computed for the whole relative data set results in significant differences $(p<0.008$ after Bonferroni correction) between all pairs of samples, except between the samples from Alaska and Greenland, Greenland and the Pacific, and between the two European samples. Therefore, the main differences between the samples are related to size, but the variation within samples precludes us from obtaining complete discrimination between our different samples of $H$. sapiens (figures 7-8).

\begin{tabular}{c|c|c|c|c|c|c|c|c|c|c|c|}
\cline { 2 - 11 } \multicolumn{1}{c|}{} & $\mathbf{W}$ & $\mathbf{H}$ & $\mathbf{2 A L}$ & $\mathbf{2 S L}$ & $\mathbf{2 A P}$ & $\mathbf{R C V}$ & $\mathbf{W r}$ & $\mathbf{H r}$ & $\mathbf{2 A L r}$ & $\mathbf{2 S L r}$ & $\mathbf{2 A P r}$ \\
\cline { 2 - 11 } & \multicolumn{8}{c|}{ Alaska, N = 78 (including $14.6 \%$-pneumatised, $12.5 \%$ with only L sinus, $4.2 \%$ with only R sinus) } \\
\hline Mean & $\mathbf{2 4 . 3}$ & $\mathbf{1 3 . 3}$ & $\mathbf{2 5 . 1}$ & $\mathbf{2 1 . 1}$ & $\mathbf{1 4 . 1}$ & $\mathbf{8 . 7}$ & $\mathbf{2 3 6 . 0}$ & $\mathbf{1 2 8 . 0}$ & $\mathbf{2 4 0 . 0}$ & $\mathbf{2 0 1 . 2}$ & $\mathbf{1 3 7 . 3}$ \\
\hline $\mathrm{V}^{*}$ & 58 & 58.7 & 60.8 & 63.4 & 59.2 & 53.3 & 50.6 & 47.4 & 49 & 50.7 & 48.5 \\
\hline
\end{tabular}

Greenland, $\mathrm{N}=48$ (including $15.4 \%$ non-pneumatised, $9 \%$ with only L sinus, $6.4 \%$ with only R sinus)

\begin{tabular}{|c|c|c|c|c|c|c|c|c|c|c|c|}
\hline Mean & $\mathbf{2 1 . 3}$ & $\mathbf{1 2 . 6}$ & $\mathbf{2 1 . 8}$ & $\mathbf{1 8 . 5}$ & $\mathbf{1 1 . 7}$ & $\mathbf{7 . 3}$ & $\mathbf{2 3 2 . 0}$ & $\mathbf{1 3 7 . 9}$ & $\mathbf{2 2 5 . 6}$ & $\mathbf{1 8 9 . 9}$ & $\mathbf{1 2 7 . 5}$ \\
\hline $\mathrm{V}^{*}$ & 73.7 & 73.5 & 82.5 & 85.1 & 76.6 & 71.8 & 64.6 & 56.1 & 60.1 & 58.8 & 56.9 \\
\hline
\end{tabular}

Poland, $\mathrm{N}=63$ (including $3.2 \%$ non-pneumatised, $11.1 \%$ with only L sinus, $1.6 \%$ with only R sinus)

\begin{tabular}{|c|c|c|c|c|c|c|c|c|c|c|c|}
\hline Mean & $\mathbf{4 1 . 4}$ & $\mathbf{2 2 . 2}$ & $\mathbf{4 1 . 1}$ & $\mathbf{4 2 . 3}$ & $\mathbf{2 5 . 7}$ & $\mathbf{1 4 . 6}$ & $\mathbf{2 6 9 . 6}$ & $\mathbf{1 4 6 . 3}$ & $\mathbf{2 6 5 . 3}$ & $\mathbf{2 6 9 . 9}$ & $\mathbf{1 6 4 . 7}$ \\
\hline $\mathrm{V}^{*}$ & 40.1 & 41.6 & 42.2 & 44.8 & 50.6 & 36.7 & 27.7 & 22.6 & 25.8 & 33.4 & 28.1 \\
\hline
\end{tabular}

Spain, $\mathrm{N}=40$ (including $7.5 \%$ non-pneumatised and $2.5 \%$ with only $\mathrm{R}$ sinus)

\begin{tabular}{|c|c|c|c|c|c|c|c|c|c|c|c|}
\hline Mean & $\mathbf{4 6 . 4}$ & $\mathbf{2 5 . 1}$ & $\mathbf{4 9 . 0}$ & $\mathbf{4 9 . 7}$ & $\mathbf{2 9 . 1}$ & $\mathbf{1 5 . 7}$ & $\mathbf{2 7 6 . 5}$ & $\mathbf{1 4 7 . 8}$ & $\mathbf{2 8 5 . 4}$ & $\mathbf{2 8 6 . 5}$ & $\mathbf{1 7 0 . 5}$ \\
\hline $\mathrm{V}^{*}$ & 42.7 & 44.9 & 43.8 & 46.9 & 51.9 & 40.8 & 34.6 & 32.6 & 32.1 & 33.9 & 36.5 \\
\hline
\end{tabular}

\begin{tabular}{|c|c|c|c|c|c|c|c|c|c|c|c|}
\cline { 2 - 10 } \multicolumn{1}{c|}{} & \multicolumn{8}{c|}{ Pacific, $\mathrm{N}=71$ (including $19.7 \%$ non-pneumatised and $4.2 \%$ with only $\mathrm{L}$ sinus) } \\
\hline Mean & $\mathbf{2 8 . 7}$ & $\mathbf{1 7 . 2}$ & $\mathbf{2 8 . 9}$ & $\mathbf{2 7 . 2}$ & $\mathbf{1 8 . 1}$ & $\mathbf{1 0 . 6}$ & $\mathbf{2 2 6 . 1}$ & $\mathbf{1 2 9 . 5}$ & $\mathbf{2 0 9 . 1}$ & $\mathbf{1 9 4 . 0}$ & $\mathbf{1 3 1 . 5}$ \\
\hline $\mathrm{V}^{*}$ & 71.6 & 74.0 & 81.6 & 83.6 & 84.4 & 70.2 & 63.8 & 54.8 & 55.4 & 57.4 & 55.9 \\
\hline
\end{tabular}

Table 6. Morphometric data (in mm for W, H, 2AL, 2SL, 2AP and RC V; the cube root of the volume of pneumatisation was used for trait size correction) for pneumatisation of the frontal bone among Homo sapiens samples / Données morphométriques (en mm pour W, H, 2AL, 2SL, 2AP et RC V; la racine cubique du volume de la pneumatisation a été utilisée pour la correction de la taille des traits) pour la pneumatisation de l'os frontal parmi les échantillons d'Homo sapiens 

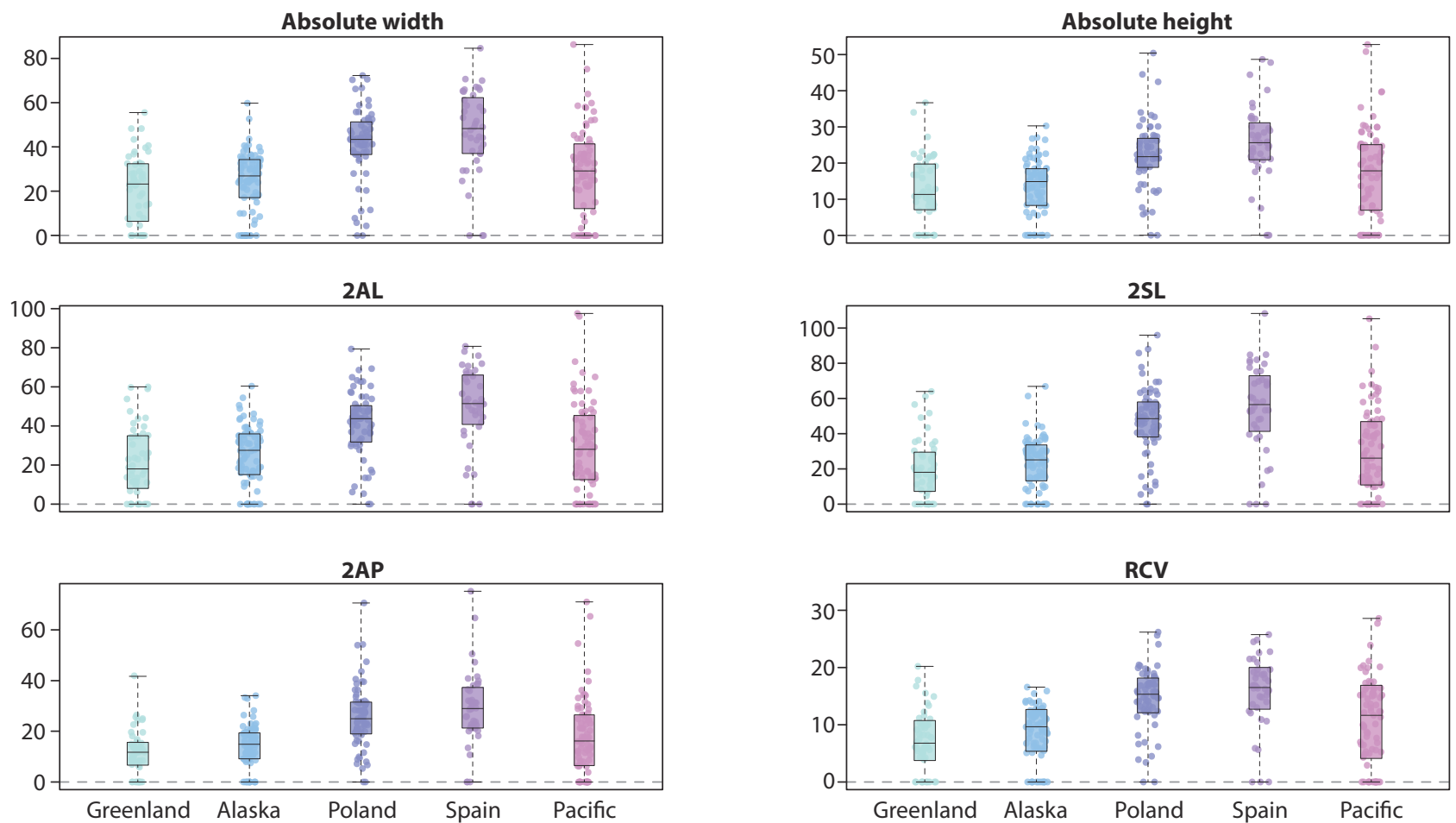

Figure 7. Absolute values for the different dimensions (in mm; width, height, $2 \mathrm{AL}$ : $\mathrm{R}+\mathrm{L}$ anterior length, $2 \mathrm{SL}$ : $\mathrm{R}+\mathrm{L}$ superior length, 2AP: combined antero-posterior dimensions and RCV: cube root of the volume of the frontal sinuses) of frontal pneumatisation in Homo sapiens samples / Valeurs absolues des différentes dimensions (en mm; largeur, hauteur, 2AL: longueur antérieure $R+L, 2 S L$ : longueur supérieure $R+L, 2 A P$ : dimensions antéro-postérieures combinées et $R C V$ : racine cubique du volume des sinus frontaux) de la pneumatisation frontale sur des échantillons d’Homo sapiens
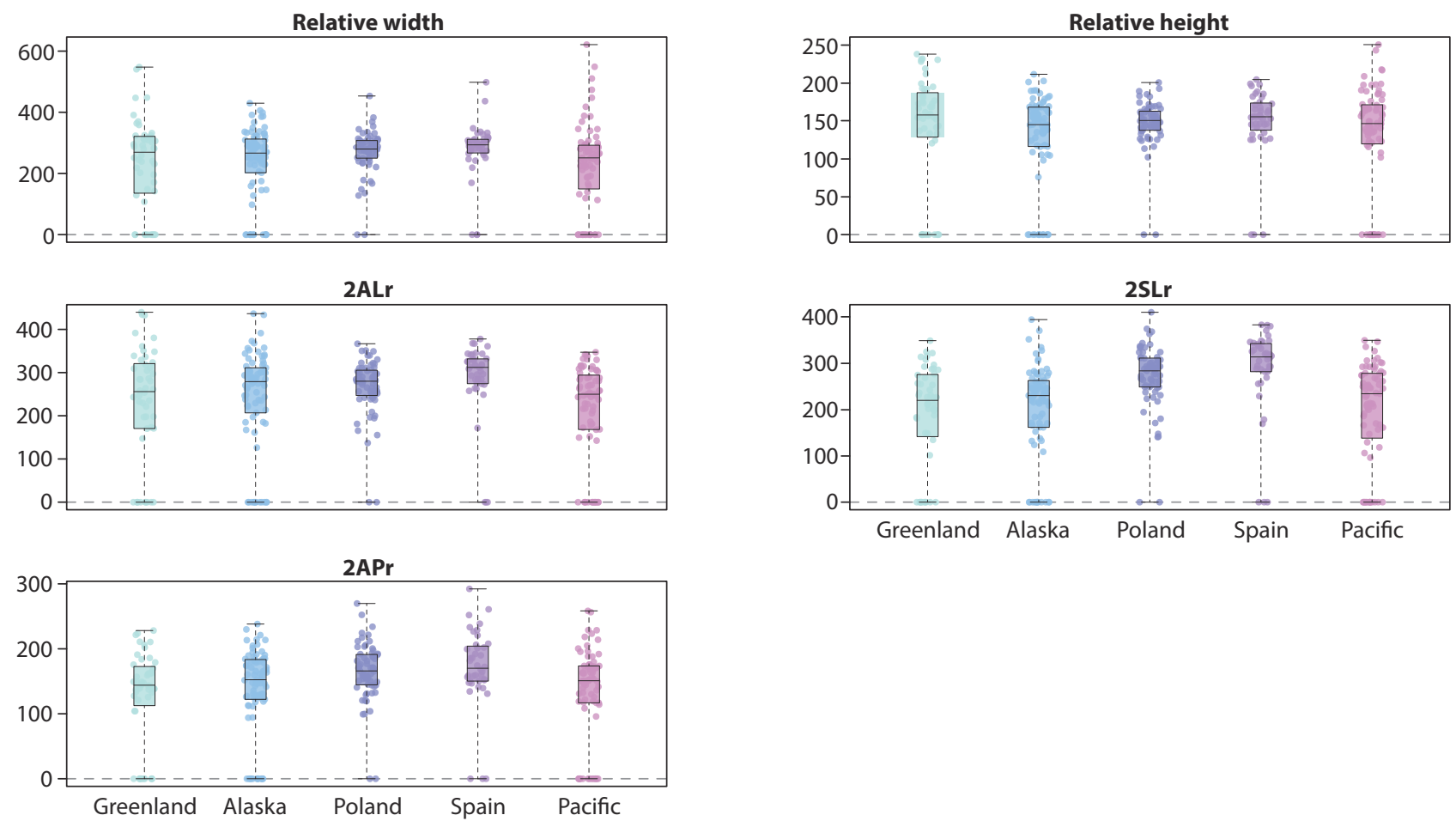

Figure 8. Relative values for the different dimensions (width, height, $2 \mathrm{AL}$ : $\mathrm{R}+\mathrm{L}$ anterior length, 2SL: $\mathrm{R}+\mathrm{L}$ superior length, 2AP: combined antero-posterior dimensions; the cube root of the volume of pneumatisation was used for trait size correction) of frontal pneumatisation in Homo sapiens samples / Valeurs relatives pour les différentes dimensions (largeur, hauteur, 2AL: longueur antérieure $R+L, 2 S L$ : longueur supérieure $R+L, 2 A P$ : dimensions antéro-postérieures combinées ; la racine cubique du volume de la pneumatisation a été utilisée pour correction de la taille du trait) de la pneumatisation frontale dans les échantillons Homo sapiens 


\section{Patterns of bilateral variation}

The difference in the maximal length of the right and left frontal sinuses (Anterior Length: ALr and ALl) in the anterior view and the difference in the maximal medio-lateral extension of the sinuses (Superior Length: SLr and SLl) in the superior view were used to quantify L-R differences. Non-pneumatised $H$. sapiens were not used in these analyses.

First, correlations between variation in departures from symmetry and the volume of pneumatisation were calculated. The cube root of the volume was tested against the values for $|\mathrm{R}-\mathrm{L}|$ (without any size correction) for AL and SL. A significant correlation ( $R M A, r=0.115, p=0.029$ ) exists for SL but not for AL $(r=-0.04, p=0.44)$. Because bilateral variation is correlated with sinus size, all subsequent analyses were conducted for size-adjusted data, which also allows comparison between samples with different extents of bilateral variation. Descriptive raw data statistics are given in the supplementary information (figures SI 1-4). Next, possible aberrant values in our database of size-adjusted values were detected (see Methods). Grubbs' test statistic identified three significant outlier data points: specimen 8608

\begin{tabular}{|c|c|c|c|c|c|}
\hline & & $\begin{array}{c}P . \\
\text { paniscus }\end{array}$ & $\begin{array}{c}P . \\
\text { troglodytes }\end{array}$ & $\begin{array}{c}G . \\
\text { gorilla }\end{array}$ & $\begin{array}{c}H . \\
\text { sapiens }\end{array}$ \\
\hline & $\mathrm{N}$ & 32 & 33 & 32 & 258 \\
\hline \multirow{6}{*}{$\mathrm{AL}$} & $\mathrm{DA}$ & 0.00 & -0.01 & -0.05 & $-0.23^{*}$ \\
\hline & FA1 & 10.01 & 4.31 & 6.22 & 7.25 \\
\hline & FA2 & 0.70 & 0.23 & 0.23 & 0.58 \\
\hline & FA4a & 0.83 & 0.24 & 0.24 & 0.71 \\
\hline & Kurtosis & -0.35 & 2.04 & -0.76 & 0.41 \\
\hline & Skew & -0.09 & -0.38 & -0.47 & -0.11 \\
\hline
\end{tabular}

\begin{tabular}{|c|l|c|c|c|c|}
\hline \multirow{5}{*}{ SL } & DA & 0.03 & -0.02 & 0.02 & -0.22 \\
\cline { 2 - 6 } & FA1 & 12.98 & 6.11 & 7.82 & 8.02 \\
\cline { 2 - 6 } & FA2 & 0.77 & 0.28 & 0.22 & 0.62 \\
\cline { 2 - 6 } & FA4a & 1.01 & 0.34 & 0.31 & 0.69 \\
\cline { 2 - 6 } & Kurtosis & -0.69 & 0.22 & -0.18 & -0.16 \\
\cline { 2 - 6 } & Skew & -0.35 & 0.35 & -0.60 & -0.19 \\
\hline
\end{tabular}

\begin{tabular}{|c|c|c|c|c|c|c|}
\hline & & Alaska & $\begin{array}{c}\text { Green- } \\
\text { land }\end{array}$ & Poland & Spain & Pacific \\
\hline & $\mathrm{N}$ & 66 & 38 & 61 & 36 & 57 \\
\hline \multirow{4}{*}{$\mathrm{AL}$} & $\mathrm{DA}$ & -0.25 & -0.28 & -0.18 & -0.06 & $-0.34 *$ \\
\hline & FA4a & 0.84 & 0.86 & 0.68 & 0.36 & 0.62 \\
\hline & Kurtosis & 0.09 & -0.23 & 0.36 & $1.68^{*}$ & 0.10 \\
\hline & Skew & 0.25 & 0.08 & -0.64 & -0.79 & -0.28 \\
\hline \multirow{4}{*}{ SL } & $\mathrm{DA}$ & $-0.23^{*}$ & -0.26 & -0.18 & -0.09 & $-0.30 *$ \\
\hline & FA4a & 0.72 & 0.81 & 0.74 & 0.40 & 0.65 \\
\hline & Kurtosis & 0.02 & -0.63 & -0.19 & 1.35 & -0.59 \\
\hline & Skew & 0.09 & 0.17 & -0.64 & -0.75 & -0.09 \\
\hline
\end{tabular}

Gorilla $(\mathrm{p}=0.003$ for AL), specimen 29074 P. troglodytes $(\mathrm{p}=0.0024$ for AL and SL), and one outlier (specimen 1907, $\mathrm{p}=0.011$ for AL and SL) in the Spanish sample of H. sapiens. These three specimens were removed from the subsequent analyses of asymmetries.

Shapiro-Wilk tests indicated a Gaussian distribution for ALr and SLr for both species of Pan and for Gorilla. AL of the combined sample for $H$. sapiens does not follow a normal distribution $(\mathrm{W}=0.96, \mathrm{p}=6.5 \mathrm{e}-06)$. Among the different samples of $H$. sapiens, the distributions of AL for the Pacific sample $(\mathrm{W}=0.95, \mathrm{p}=0.026)$, and AL $(\mathrm{W}=0.94$, $\mathrm{p}=0.01)$ and SL $(\mathrm{W}=0.96, \mathrm{p}=0.036)$ for the Polish sample are significantly not normal after Bonferroni correction.

Indicators of directional asymmetry were identified through statistical analyses and observation of the distribution of the samples (tables 7-8, figures 9-10). Based on t-tests followed by Bonferroni correction, DA is significantly different from zero for AL ( $p=2 e-04)$ and SL (2e-04) for the whole sample of $H$. sapiens, for AL $(p=0.004)$ and $\mathrm{SL}(\mathrm{p}=0.007)$ in the Pacific sample and for SL $(\mathrm{p}=0.046)$ in the Alaska sample. None of the other variables and/or other samples for H. sapiens or Pan and Gorilla showed

Table 7. Descriptive statistics for the anterior and superior lengths of the frontal sinuses in Pan, Gorilla and Homo sapiens, including classic parameters of variation (number of individuals $(N), D A=$ mean value for the relative values for $(R-L), F A 1$ :

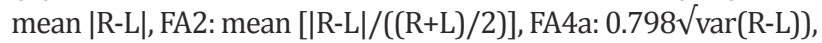
values for kurtosis and skewness, *indicates a significant value / Statistiques descriptives des longueurs antérieure et supérieure des sinus frontaux chez Pan, Gorilla et Homo sapiens, y compris les paramètres classiques de variation ( $n b$ d'individus ( $N$ ), $D A=$ valeur moyenne des valeurs relatives pour (RL), FA1 : moyenne

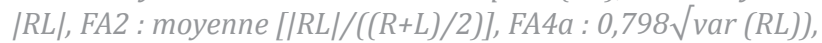
valeurs pour le coefficient d'asymétrie et le coefficient d'aplatissement, ${ }^{*}$ indique une valeur significative

Table 8. Descriptive statistics for the anterior and superior lengths of the frontal sinuses in geographically diverse samples of Homo sapiens, including classic parameters of variation (number of individuals $(\mathrm{N}), \mathrm{DA}=$ mean value for the relative values for (R-L), FA4a: 0.798 $\sqrt{\operatorname{var}(R-L)), ~ v a l u e s ~ f o r ~ k u r t o s i s ~ a n d ~ s k e w n e s s, ~}$ *indicates a significant value / Statistiques descriptives des longueurs antérieure et supérieure des sinus frontaux dans des échantillons géographiquement diversifiés d'Homo sapiens, y compris les paramètres classiques de variation ( $\mathrm{nb}$ d'individus $(N), D A=$ valeur moyenne des valeurs relatives pour (RL), FA4a : $0,798 \sqrt{ }$ var $(R L))$, valeurs pour le coefficient d'asymétrie et le coefficient d'aplatissement, * indique une valeur significative 
DA Anterior length

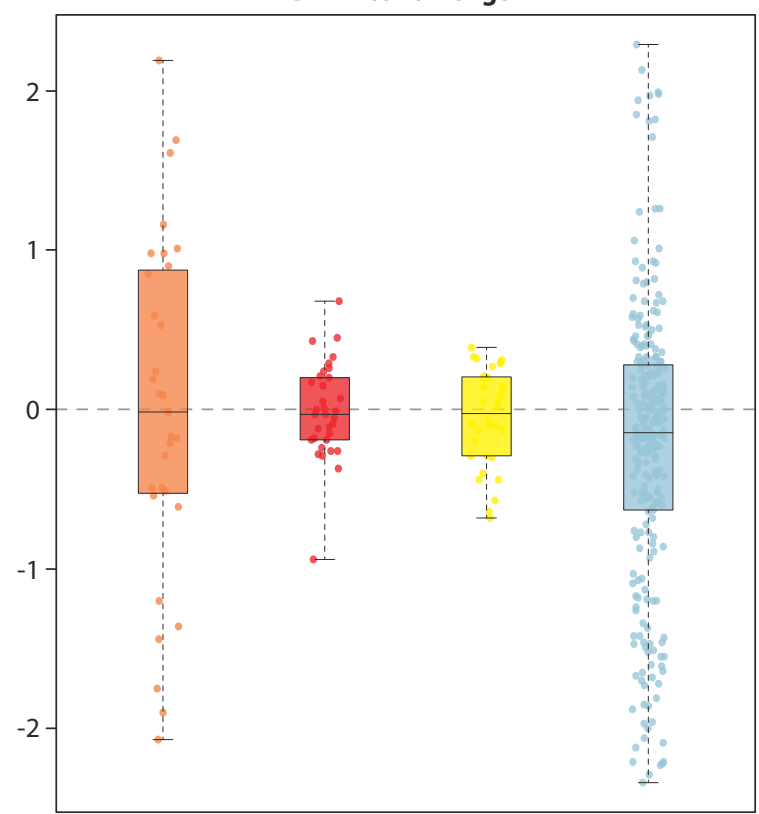

P.paniscus P.troglodytes G.gorilla H.sapiens

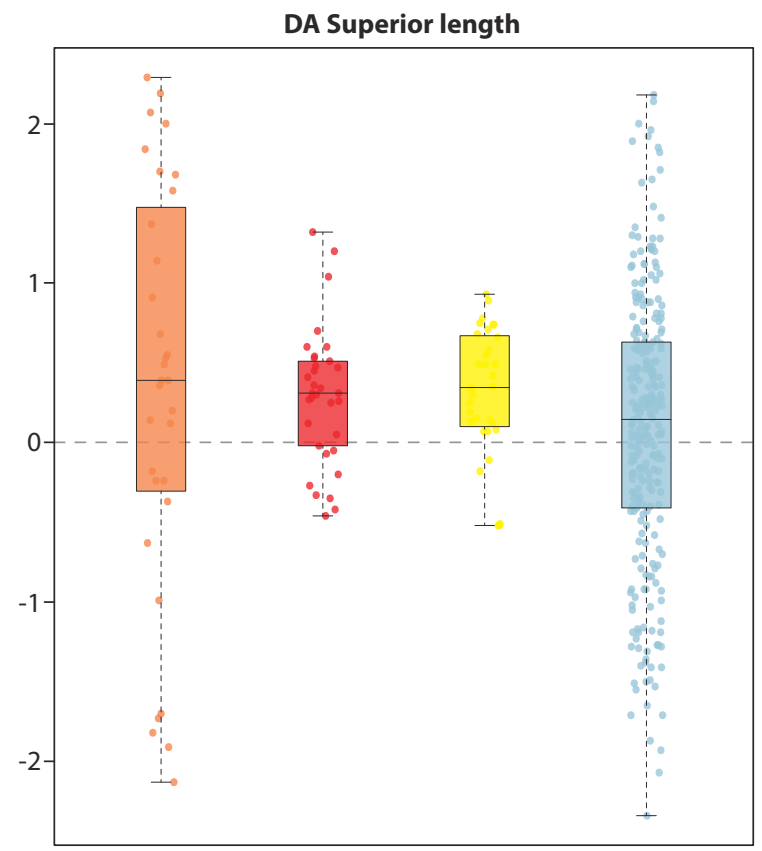

P.paniscus P.troglodytes G.gorilla H. sapiens

Figure 9. Boxplots displaying the distribution of directional asymmetry (DA = R-L) for size-corrected anterior and superior lengths of the frontal sinuses (the cube root of the volume of pneumatisation was used for trait size correction) in Pan, Gorilla and Homo sapiens, showing the median, the inter-quartile range, the most extreme data points, and all data points as individual points (dots) / Boites à moustaches des valeurs d'asymétrie directionnelle (DA $=R-L)$ des longueurs antérieure et supérieure corrigées de la taille des sinus frontaux (la racine cubique du volume de la pneumatisation a été utilisée pour la correction de la taille des traits) chez Pan, Gorilla et Homo sapiens montrant la médiane, les quartiles, les points de données qui sont les plus extrêmes, et tous les points de données sous forme de points individuels (points)
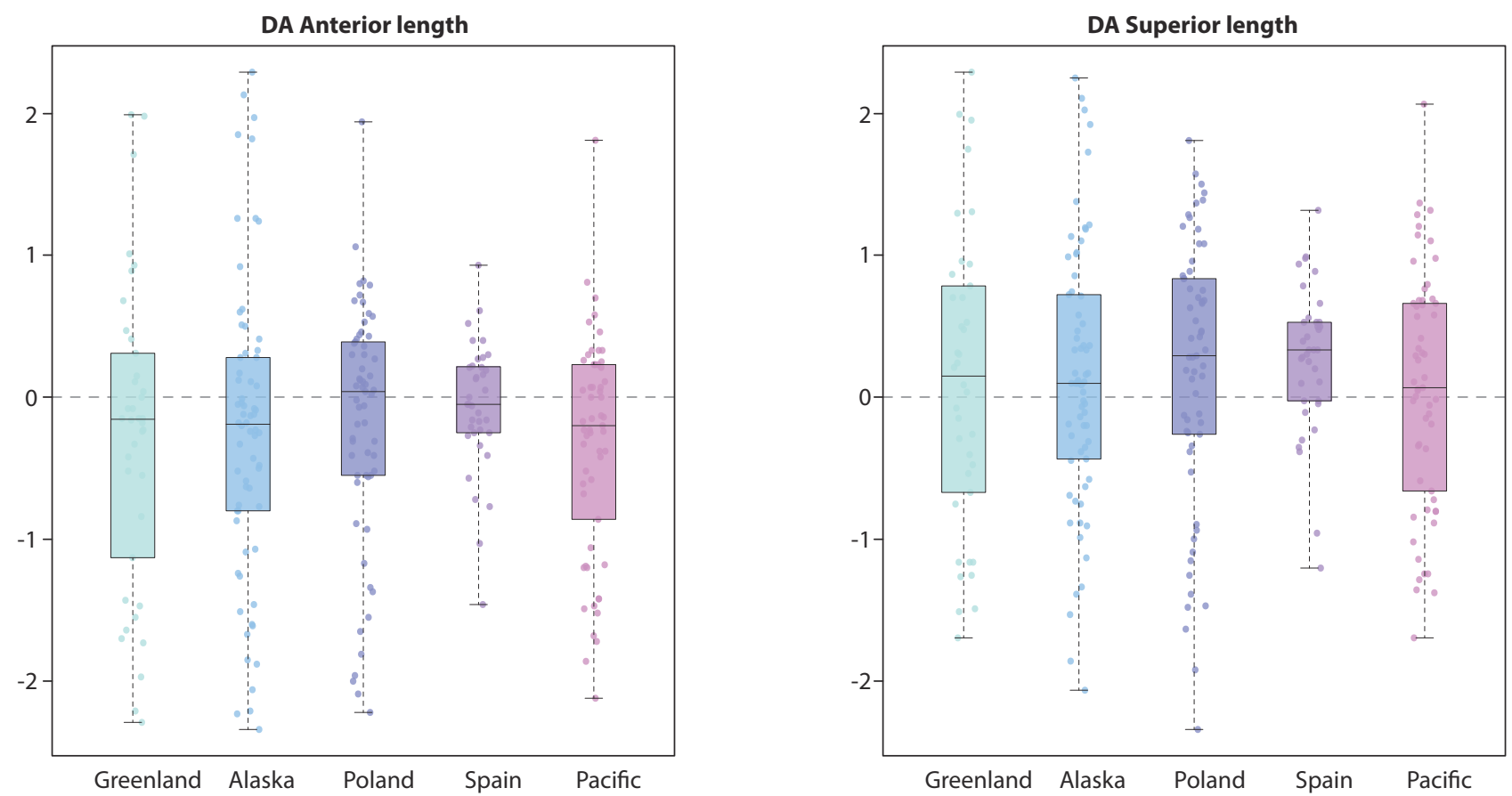

Figure 10. Boxplots displaying the distribution of directional asymmetry (DA = R-L) for anterior and superior lengths of the frontal sinuses (the cube root of the volume of pneumatisation was used for trait size correction) in Homo sapiens samples showing the median, the inter-quartile range, the most extreme data points, and all data points as individual points (dots) / Boites à moustaches des valeurs d'asymétrie directionnelle $(D A=R-L)$ pour les longueurs antérieures et supérieures des sinus frontaux corrigées par la taille (la racine cubique du volume de la pneumatisation a été utilisée pour la correction de la taille des traits) dans des échantillons d'Homo sapiens montrant la médiane, les quartiles, les points de données qui sont les plus extrêmes, et tous les points de données sous forme de points individuels (points) 
significant DA. However, all samples of H. sapiens have a tendency towards a larger left sinus in the anterior and superior view compared to the right sinus, as expressed by negative values for DA (table 8). Mean values are also negative in both species of Pan and Gorilla, but they are very low (table 7). Among the different samples of $H$. sapiens, there is some variation in the orientation of the asymmetric pattern in the anterior orientation (figure 8), while the orientation is always towards the left for the measurement in the superior orientation.

Several additional observations are informative regarding the patterns of variation around the mean for departures from symmetry (tables 7-8, figures 11-12). The values for FA1 and FA2 both decrease from $P$. paniscus to $H$. sapiens, $G$. gorilla and through to $P$. troglodytes. No significant skewness, platykurtosis or leptokurtosis was detected in Pan and Gorilla. The variation (as expressed by the respective values for FA1, FA2 and FA4a) is much larger in bonobos and comparatively lower in chimpanzees and gorillas while the intermediate values for $H$. sapiens are accompanied by the presence of significant DA. The histogram for the whole sample of $H$. sapiens (figure 11) is clearly indicative of those characteristics.

In the different $H$. sapiens samples, there is significant leptokurtosis for AL (kurtosis $=1.68, \mathrm{p}<0.05$ ) and high (but not significant) negative values for skewness for AL $(-0.79)$ and SL (-0.75) in the Spanish sample. The values for kurtosis and skewness are low for all the other variables. These results are consistent with the presence of DA and the absence of antisymmetry. The mean values for R-L (or DA) are always smaller than FA4a for Pan and Gorilla and for all samples of $H$. sapiens. This means that the prevalence of one side is less than the average deviation around the mean, which may point to developmental instability (see Methods). The global characteristics of the distributions are quite similar in the different samples of $H$. sapiens (figure 12).
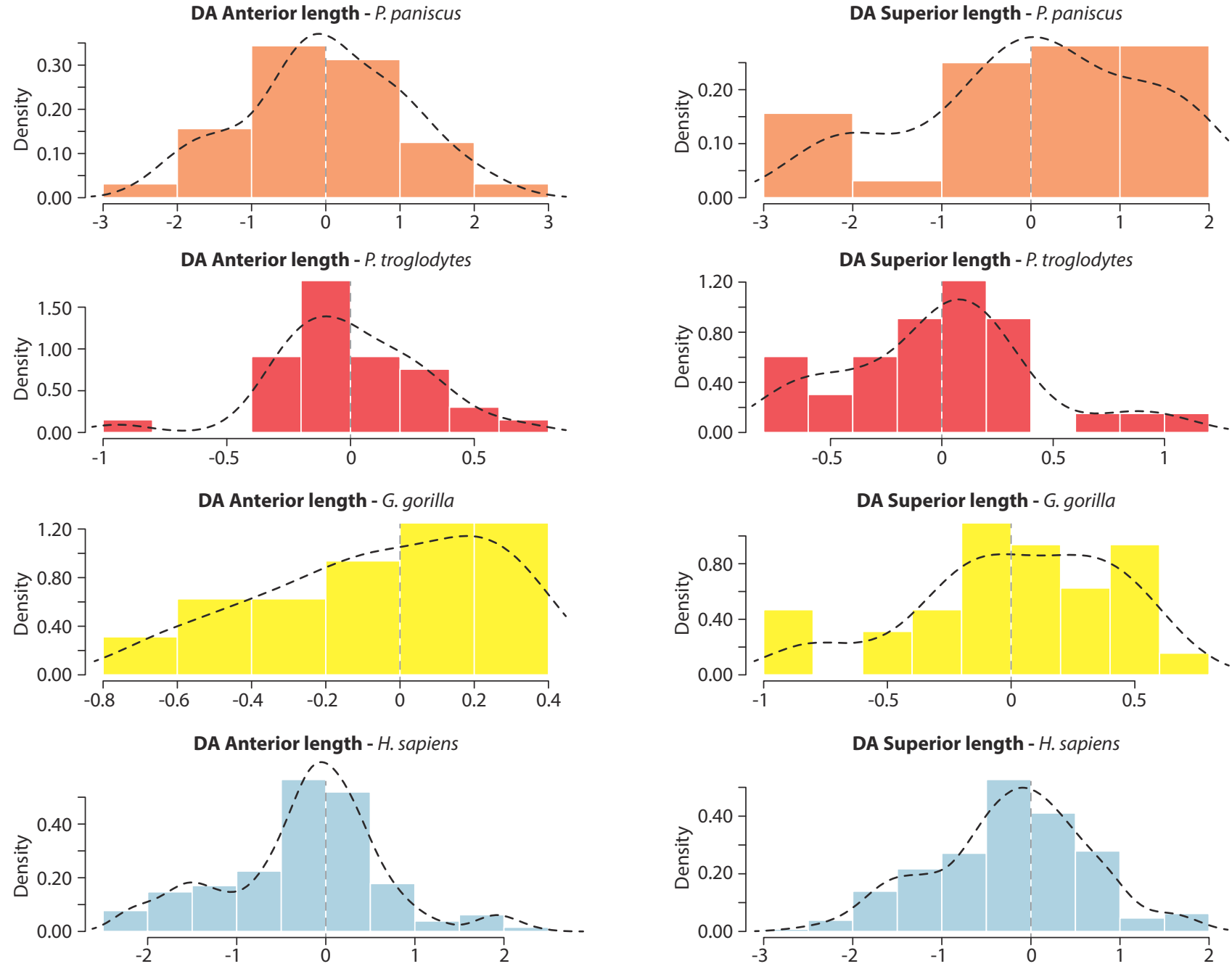

Figure 11. Density distribution of size-corrected (R-L) anterior and superior lengths of the frontal sinuses in Pan, Gorilla and Homo sapiens (the cube root of the volume of pneumatisation was used for trait size correction) / Distribution de densité des longueurs antérieure et supérieure corrigées de la taille (R-L) des sinus frontaux chez les Pan, Gorilla et Homo sapiens (la racine cubique du volume de la pneumatisation a été utilisée pour la correction de la taille des traits) 


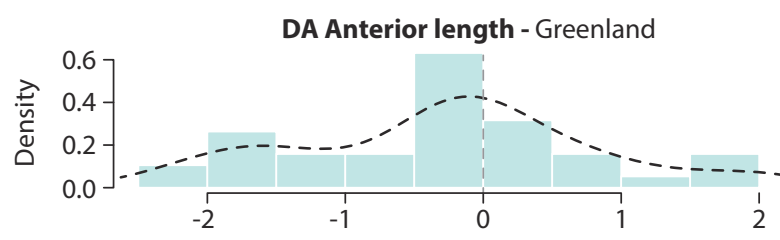

DA Anterior length - Alaska

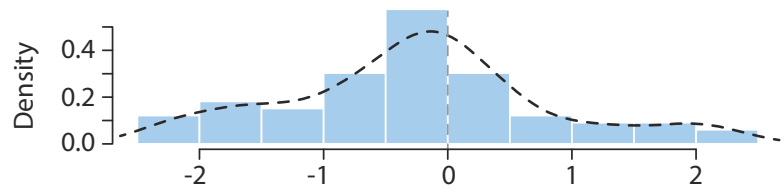

DA Anterior length - Poland

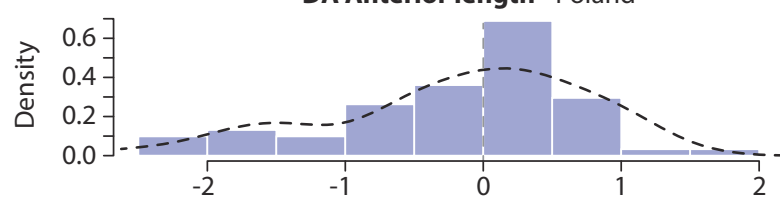

DA Anterior length - Spain

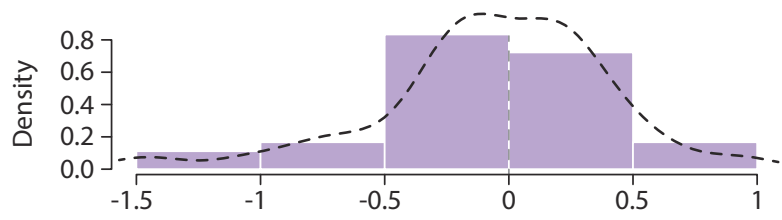

DA Anterior length - Pacific

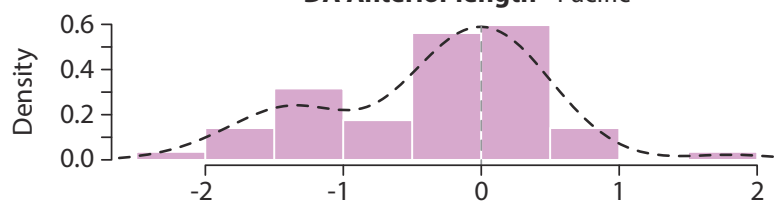

DA Superior length - Greenland

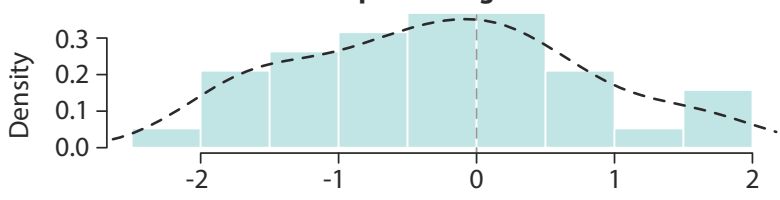

DA Superior length - Alaska

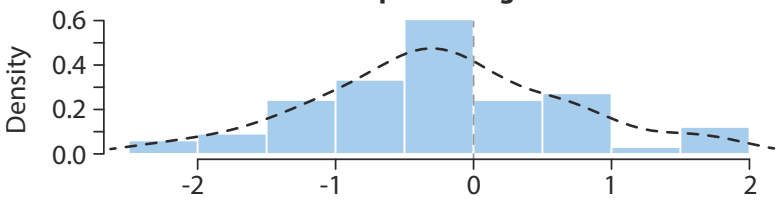

DA Superior length - Poland

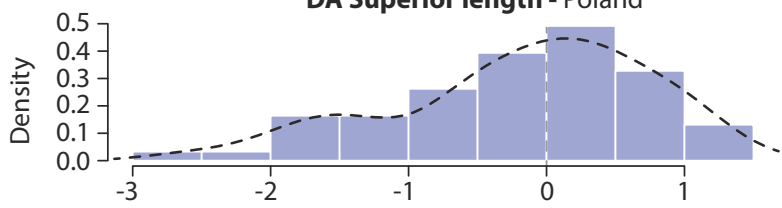

DA Superior length - Spain

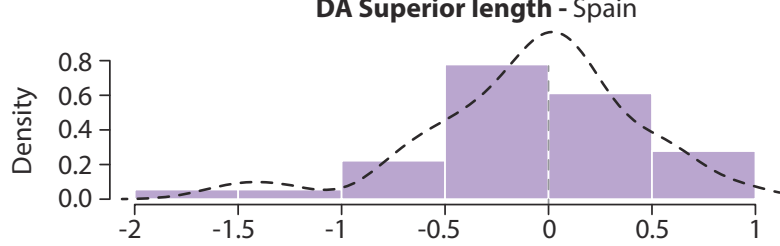

DA Superior length - Pacific

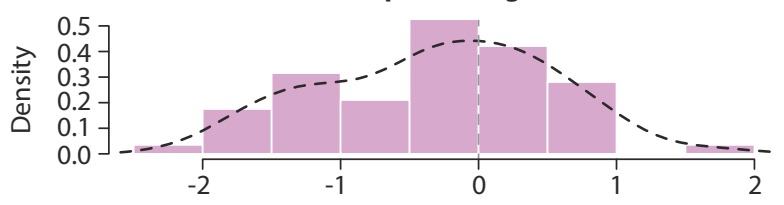

Figure 12. Density distribution of size-corrected (R-L) anterior and superior lengths of the frontal sinuses in Homo sapiens samples (the cube root of the volume of pneumatisation was used for trait size correction) / Distribution de densité des longueurs antérieure et supérieure corrigées de la taille $(R-L)$ des sinus frontaux dans les échantillons d'Homo sapiens (la racine cubique du volume de la pneumatisation a été utilisée pour la correction de la taille des traits)

\section{Frontal sinuses and brain endocast asymmetries}

Potential correlation between the pattern of bilateral distribution for the frontal sinuses and the brain petalia was also explored. The latter feature corresponds to the relative anterior and lateral expansion of the right and left frontal lobes. There are no significant correlations between the different parameters for the petalias and the absolute values for (R-L) for AL and SL in the different samples of Pan and Gorilla. Among the $H$. sapiens samples, there is a significant correlation, after Bonferroni correction, between the (R-L) vertical petalia and the (R-L) anterior (RMA regression, $\mathrm{r}=0.315, \mathrm{p}=0.009$ ) and superior (RMA regression, $\mathrm{r}=0.287$, $\mathrm{p}=0.018$ ) lengths of the frontal sinuses. This means that when there is a tendency for one sinus to be larger than that on the other side, it is related to the more elevated position of the frontal pole on the same side. In other words, it seems likely that when the frontal pole is in a more elevated position, the sinus has more space to develop and a significant
$\mathrm{R} / \mathrm{L}$ difference is visible for those parameters. In $H$. sapiens, the left frontal sinus tends to be larger than the right sinus (table 8) and there are more specimens with unilateral pneumatisation on the left side than on the right side. This fits with the observation that more than $95 \%$ of the specimens show a right frontal petalia, following the definition of Holloway and de la Coste-Lareymondie (1982), which also includes a larger lateral development of the right frontal lobe relative to the contralateral side.

\section{Discussion}

The frontal sinuses of Pan and Gorilla, state of the art

The frontal sinuses of adult gorillas were previously reported to be large (Cave, 1961); here we report a quantification of those parameters and revise the previous observations, which were based on small Gorilla and Pan samples (Blaney, 1986). Blaney (1986) reports smaller volumes for 
pneumatisation in gorillas in the combined (male and female) sample compared to our values. On the other hand, his estimates for the same categories in chimpanzees are larger than ours. This might be reasonably explained by variation in methodologies, as Blaney (1986) calculated an estimate of the volume. Similarly, his observation of the absence of frontal sinuses in two gorillas and one chimpanzee (Blaney, 1986) is probably related to the use of radiographic data and the density of the bone in the primate skulls analysed. Unfortunately, the corresponding images were not published and are not available for re-analysis.

In the present study, the mean volumes of the sinuses are larger in males compared to females in P. troglodytes and $G$. gorilla. The mean volume is larger in $P$. paniscus females and this difference is intriguing, although it does not reach significance. Sample size may partly explain this discrepancy and additional studies on larger samples will be necessary to assess whether sexual variation in the expression of these traits has some biological origin. In any case, this pattern is also likely to be related to lower absolute values and larger variation for all the parameters analysed in $P$. paniscus relative to $P$. troglodytes and $G$. gorilla, and to lower levels of sexual dimorphism within P. paniscus (Shea, 1983).

Blaney (1986) reports that frontal sinus volume scales positively with skull length in gorillas and chimpanzees. Different slopes in this correlation between the two samples led him to conclude that the frontal sinuses of gorillas are relatively smaller than those of chimpanzees. This observation is strongly influenced by variation in the shape of the skull in gorillas: a large supraorbital torus and occipital crest are visible in gorillas, reaching a very large extension in the most robust males. This large variation in cranial superstructures makes skull length a poor determinant of overall cranial size for this species. Here, the relationship between sinus form and endocranial size is examined, which avoids the issue of the superstructures and is less affected by sexual dimorphism. Other measures of craniofacial size, however, such as those focusing on the face, could produce different results. A significant correlation between the cube root of the volume of the frontal sinuses and the cube root of the endocranial volume exists within the whole Pan and Gorilla sample analysed here (figure 3 ). In detail, the slope of the relationship is slightly lower in gorillas compared to chimpanzees and bonobos. In contrast to Blaney, here, in the nonhuman primate taxa that exhibit ethmoidally-derived frontal sinuses, namely G. gorilla, P. troglodytes and P. paniscus, the frontal sinuses show a significant correlation with cranial size when estimated via the endocranial volume.

\section{What was previously known about the frontal sinuses of Homo sapiens?}

Comparisons between the current analyses and previous studies regarding data on $H$. sapiens are not easy. The main reason for this is that the majority of earlier studies used radiographic data to estimate linear or volumetric data, which is not easily comparable with the information presented here. Many studies have also excluded non-pneumatised specimens from their calculations of mean values. Notwithstanding potentially incompatible methodologies, decades of research have shown that frontal sinus size varies considerably, both within and among populations (e.g. Brothwell et al., 1968; Buckland-Wright, 1970; Tillier, 1975; 1977; Pondé et al., 2003; Uthman et al., 2010). To date, however, there have been few large-scale studies of frontal sinus size with global sample distributions. Instead, most researchers have focused on a single population or region, often due to the medical context of the research (e.g. Tatlisumak et al., 2008; Tang et al., 2009; Flanigan et al., 2016; Soman et al., 2016). From the existing literature, no clear pattern of amongpopulation differences has arisen and therefore the correlates of frontal sinus morphology in humans remain unclear.

There is a long-standing theory that sinus size relates to climatic adaptation (see Introduction). This theory was originally developed to explain the allegedly large sinuses of Neandertals (e.g. Churchill, 1998), but it has also been used to explain, conversely, the small frontal sinuses observed in some high latitude groups of $H$. sapiens (Koertvelyessy, 1972; Tillier, 1975; 1977; Hanson and Owsley, 1980), a trend visible in the current data. A climatic cline in frontal sinus size is far less clear, however, when wider cross-population comparisons are made (Buck, 2014; Butaric et al., in review). More frequently, recent cross-population studies have tended to focus on the maxillary sinuses, where there is evidence for a relationship between sinus size and nasal morphology (and thus among-population variation) that may indeed be partially ascribed to secondary climatic adaptation via adaptation in the nasal apparatus (Holton et al., 2013; Butaric and Maddux, 2016; Maddux and Butaric, 2017). The morphology of the different types of sinuses (i.e., frontal, maxillary, sphenoidal and ethmoid), however, seems to be shaped by different factors, leading to relatively independent development (Tillier, 1975; Buck, 2015; Buck et al., 2019). Thus, a potential eco-geographical pattern in maxillary sinuses should not be extrapolated to frontal sinuses: although we observed a certain degree of variation here between the different samples analysed for H. sapiens (figures 7-8), no clear pattern emerges.

The existing literature on the topic of sexual dimorphism in frontal sinuses in humans shows varying degrees of accuracy in attempts to identify sex in humans based on dimensions of the frontal sinuses, with correct determination ranging for example between 54\% (Nethan et al., 2018), 55.2\% (Verma et al., 2014), 64.8\% (Beladavar et al., 2014) and $81.8 \%$ (Shireen et al., 2019) with different samples and using various methodologies. If the low determination rates in humans are not just due to methodological issues, these results, together with our observations here, suggest a lesser degree of sexual dimorphism in frontal sinus size within $H$. sapiens than within chimpanzees or gorillas. On the other hand, human frontal sinuses are so variable that they are used to identify individuals in forensic contexts (Gadekar et al., 2019; Kumar et al., 2018; Nikam et al., 2015; 
Cvrček et al., 2020), which shows that there is substantial variation within and between different samples of $H$. sapiens (Buck et al., 2019; Rennie et al., 2017; Tatlisumak et al., 2016; Kim et al., 2013). Studies with very large samples, well-documented geographic origins and independent sex assessment would be necessary to explore a potential sexually-determined pattern of sinus form. However, based on the available evidence, size and shape variation in the frontal sinuses seems to be a poor indicator for sex assessment in H. sapiens.

\section{New information on variation in frontal sinus characteristics}

The frontal sinuses show a significant correlation with endocranial volume in Pan and Gorilla. In H. sapiens there is, on the contrary, considerable variation in sinus size between samples, a larger proportion of non-pneumatised specimens (as visible in figure 7, RCV; see also table 6), and lower values for sinus volume compared to the Pan and Gorilla samples analysed here (table 5 and figure 4, RCV). In addition, these data are supported by our results for the Spanish sample. All these data suggest that $H$. sapiens does not follow the relationship observed in Pan and Gorilla between sinus volume and endocranial volume. The brain is indeed much larger in $H$. sapiens while the sinuses are much smaller both absolutely and relatively.

Sardi and collaborators (2018) recently reached the same conclusion of an absence of relationship between sinus volume and the endocranial volume in a sample of 149 living humans. They also observed a positive relationship between sinus size and bone thickness, an aspect that deserves further investigation. As a result, the trend of a positive correlation between frontal sinus size and endocranial volume observed in Pan and Gorilla does not include $H$. sapiens. Contrary to what we observe in chimpanzees, bonobos and gorillas, our species has smaller sinuses and a larger brain, and no relationship between those dimensions. Moreover, our relatively smaller frontal sinuses are more variable in shape and size than in those of the other species analysed here.

This disconnect between sinus size and endocranial size in humans may be due to several factors: modifications from the shared Pan and Gorilla pattern in the timing, intensity and duration of the growth and development of the sinuses, change related to the influence of brain expansion and how human encephalisation has modified cranial integration and/or modification in external parameters that influence sinus expansion. It is likely that the condition observed in our species is an autapomorphic state compared to G. gorilla, $P$. troglodytes and P. paniscus. The feature is not observable in any outgroup to help establish the polarity of the group. However, Pan and Homo are generally considered as a clade, Gorilla being rooted more deeply. For this reason, we consider that a character state shared by Gorilla and Pan is plesiomorphic if another condition is observed in Homo. Further studies of the fossil hominin record will help to understand when this condition appeared and to decipher its underlying causes. These aspects will also have to be studied in the future while considering the relative position of the orbits, the frontal bone and the frontal lobes (e.g. Beaudet and Bruner, 2017; Pereira-Pedro et al., 2017). This is because morphological integration between these elements could affect the size and shape of the frontal sinuses.

The present study provides an extensive and detailed exploration of morphometric variation in frontal sinuses. In terms of absolute dimensions, the mean values for G. gorilla are larger than those for $P$. troglodytes, which are larger than those for $P$. paniscus, which in turn are larger than those for $H$. sapiens. This pattern is true for all the variables analysed here that consider the width, height, anteroposterior extension and volume of the sinuses (table 5, figure 4). The two exceptions are the mean values for the width and the height of the sinus in $H$. sapiens, which slightly exceed those for $P$. paniscus. The observed variation within each sample is smaller for all variables in gorillas, larger in chimpanzees and even larger in bonobos. Finally, the observed variation for $H$. sapiens far exceeds the values for the Pan and Gorilla samples. When relative dimensions are considered (table 5, figure 5), the pattern is different in relation to different mean shapes between species. G. gorilla is particularly characterised by a relatively large width in the superior view and a relatively large antero-posterior extension. H. sapiens is at the opposite end of the range of variation for these two variables (figures 6-7). P. paniscus has the most similar frontal sinus characteristics to $H$. sapiens. However, when all parameters are considered, there are clear differences in frontal pneumatisation between $P$. paniscus, P. troglodytes, $G$. gorilla and H. sapiens in terms of both size and shape.

\section{Bilateral variation of the frontal sinuses}

There is a significant correlation between the size of bilateral asymmetries and the size of the sinuses for the parameter SL, but not for AL in the whole set of samples analysed. SL is a measurement taken in the superior view that quantifies the lateral extension of the sinuses but also, partly, their antero-posterior extension. AL, on the contrary, quantifies a lateral component but also, partly, the vertical extension of the sinuses. This illustrates that the development of pneumatisation is less plastic vertically, as it is constrained by the upper extension of the frontal superstructures. The space available in the lateral and antero- posterior directions inside the frontal bone allows for more variation in the bilateral position and extension of the frontal sinuses.

Bilateral variation in all directions follows a normal distribution in Pan and Gorilla, whereas ALr does not in H. sapiens. No directional asymmetry (DA) was detected in Pan and Gorilla, whereas the left sinus is significantly larger than the right sinus in the different dimensions measured here for the whole H. sapiens sample. In Pan and Gorilla, the asymmetries observed in the frontal lobes of the brain are not related to any bilateral variation in the expression of the frontal sinuses. Examination of a subsample of $H$. sapiens, 
on the other hand, reveals a significant correlation between the extension of the brain petalias and bilateral variations in the extension of the sinus. A clear tendency is observed towards a more anteriorly and laterally projected right frontal lobe compared to the left lobe, while the right frontal sinus has a reduced lateral and antero-posterior extension compared with the left frontal sinus. We thus demonstrate that the pattern of frontal asymmetries of the brain is related to, and plausibly influences, the bilateral development of the frontal sinuses in $H$. sapiens. It is likely that this relationship is observed in H. sapiens and not in Pan and Gorilla for several interrelated reasons. The degree and size of the petalias is larger in H. sapiens (Balzeau and Gilissen, 2010; Balzeau et al., 2012; Neubauer et al., 2020), potentially resulting in greater constriction of frontal sinus growth. Moreover, the available space for the expansion of the frontal sinuses is further restricted due to the smaller frontal superstructures in H. sapiens compared to Pan and Gorilla. In this context, the interaction between the expression of frontal pneumatisation and asymmetries of the frontal lobes also appears to be a derived characteristic of $H$. sapiens relative to G. gorilla, P. troglodytes and P. paniscus. Observation of the fossil hominin record will allow the patterns of this particular condition to be explored.

\section{Causes and patterns of form in frontal sinuses}

There is a clear difference between Pan and Gorilla and $H$. sapiens in the bilateral variation of the sinuses, which has a number of implications. The larger space available inside the frontal superstructures in Pan and Gorilla means that there is only limited pressure during the growth and development of the two frontal sinuses. This is supported by the normal distribution of the R-L dimension of the sinus and the absence of DA and FA in Pan and Gorilla. Moreover, very few Pan and Gorilla specimens show unilateral development of pneumatisation. In $H$. sapiens, on the other hand, there are significant DA and stronger indicators of FA, as well as a $10.7 \%$ ratio of unilateral pneumatisation. Our sample of $300 \mathrm{H}$. sapiens also has $12.7 \%$ specimens entirely without frontal sinuses. The vertical frontal squama and its limited thickness in $H$. sapiens seem to constrain sinus development. Our results also suggest an influence of frontal lobe asymmetries on the relative development of the sinuses on each side. This being the case, it is likely that the frontal sinuses in Pan and Gorilla are less constrained and fill the available space in the frontal bone, with some peculiarities within each species relating to their respective frontal bone form. In H. sapiens, frontal sinus development is constrained by the shape of the brain and the small available space within the frontal bone. It has previously been posited that sinuses passively expand into available space, different shaped crania leading to different sinus morphology (e.g. Moss and Young, 1960; Shea, 1977; Blaney, 1990; Vinyard and Smith, 1997; Zollikofer et al., 2008); the combination of a Pan, Gorilla and $H$. sapiens sample and data describing both endocranial and sinus morphology supports this argument.
The most common explanation for the presence of frontal sinuses is that large sinuses serve to condition inspired air in cold environments (e.g. Coon, 1962; Churchill, 1998; Wolpoff, 1999). In fact, as mentioned above, frontal sinus size in H. sapiens actually decreases in cold environments (Koertvelyessy, 1972; Hanson and Owsley, 1980). Our study supports the latter findings. Amongst the $H$. sapiens samples, smaller sinuses are found in the samples from Greenland and Alaska (figure 6). The mean values for sinus size are respectively larger in the sample from the Pacific area, in the Polish sample and finally in the Spanish sample. The variation for all dimensions is larger in the samples from Greenland and the Pacific, followed by the sample from Alaska, compared to the two European samples. The Pacific sample is made up of diverse populations from separate islands dispersed across a vast geographical area. As a result, we cannot observe any clear trend between geography and frontal sinus shape and size. Based on these data, it is not clear how any direct link could be proposed between sinus size and climate.

A significant correlation exists between frontal sinus size and endocranial volume in P. paniscus, $P$. troglodytes and G. gorilla, independently of the large variation in cranial form among those species and combined with distinct sexual dimorphism. This reflects a general relationship between sinus size and body size in Pan and Gorilla. It also weakens the possibility of a strong functional origin for the variation in size and shape of their frontal sinuses. The considerable variation in $H$. sapiens sinus metrics, as well as the smaller dimensions of the sinuses compared to the other taxa, illustrates different mechanisms at work in humans compared with Pan and Gorilla. As discussed above, the variation in size and shape within samples does not support the climate hypothesis, although an effect of extreme cold stress at very high latitudes combined with a neutral pattern of variation throughout most of the world remains theoretically possible. To date, no other satisfactory functional explanation emerges from the literature. As a result, although a functional origin of frontal pneumatisation cannot be rejected, the available information tends to show that the evolution of frontal pneumatisation followed a complex scenario.

In this context, frontal sinus shape and size could be potential phylogenetic markers in primate systematics. Pan, Gorilla and Homo are the only primates to have ethmoidally-derived frontal sinuses. The condition common to P. paniscus, $P$. troglodytes and G. gorilla is likely to be primitive relatively to $H$. sapiens, given that Pan and Homo are sister taxa, as discussed above. Of the taxa investigated here, non-human frontal sinus form is mainly related to the allometric trend observed among those species. However, specificities in frontal pneumatisation exist between those taxa. The G. gorilla sample is particularly characterised by a relatively large width in the superior view and a relatively large antero-posterior extension. H. sapiens differs from the other hominines studied here in having relatively smaller frontal sinuses that are more variable in shape and size, with restricted relative lateral and antero-posterior 
extension and whose development is not related to endocranial size. Studies of the fossil hominin record will be decisive to understand when this latter apomorphic condition appeared and whether frontal bone pneumatisation has good potential for clarifying hominin taxonomy. It will also allow further exploration of how the form of the brain, face and sinuses are integrated.

\section{Conclusions}

This study complements previous knowledge of the biological diversity of the frontal sinuses in Pan and Gorilla and among various samples of $H$. sapiens, and provides an insight into the origin of this diversity. Ethmoidally-derived frontal sinuses thus appear as a complex structure during the evolution of primates. Absent in most taxa, they show common characteristics of shape and size in chimpanzees, bonobos and gorillas, yet are markedly more variable in the globally distributed $H$. sapiens. In $P$. troglodytes, $P$. paniscus and $G$. gorilla, the shape and size of this pneumatisation follow a relationship with endocranial volume, whereas this link is not present in H. sapiens. This suggests that the larger space available in the bony superstructures of Pan and Gorilla gives the sinuses the opportunity to develop under only slight constraint from their surrounding structures. In our own species, the variation observed in the shape, arrangement and bilateral variation of the frontal sinuses is much greater than in Pan and Gorilla. In H. sapiens, the more vertical position of the frontal bone, its reduced thickness, the reduction in bony relief on the eye sockets and the greater influence of the frontal lobes have most likely modified the integration between the cranium, brain and frontal sinuses. Future study of the human fossil record will make it possible to document the pattern and chronology of the establishment of these new characteristics.

\section{Acknowledgments}

We wish to thank the following institutions and individuals for allowing us to use imaging data in their care: L Copes, Frank H Netter MD School of Medicine, Quinnipiac University, USA; E Gilissen, W Wendelen, Department of African Zoology, Royal Museum for Central Africa, Tervuren, Belgium; A Rosas, A Garcia-Tabernero, Grupo de PaleoAntropologia MNCN-CSIC, Department of Paleobiology, Museo Nacional de Ciencas Naturales, Madrid, Spain; A Wrzesińska, Museum of the First Piasts at Lednica, Ostrów Lednicki, Poland. This research was partly conducted during the PaleoBRAIN project funded by the French research agency (ANR-20-CE27-0009-01). We thank the co-editor in chief of the BMSAP in charge of this paper as well as the two reviewers, Emiliano Bruner and Todd Rae, who provided very helpful comments to improve our paper and Ilona Bossanyi. Thanks also to the Société d'Anthropologie de Paris and to the BMSAP for the opportunity to publish this paper in diamond open access. This is the policy that offers the best opportunities for the future of academia in the context of scientific ethics and critical rationalism. We believe that this approach is the future of scientific research and that it deserves consideration by all scientists.

\section{References}

Amrhein V, Greenland S, McShane B (2019) Scientists rise up against statistical significance. Nature 567:305-307

Ball-Albessard L (2018) Co-variation morphologique du crâne et de l'endocrâne au cours de l'évolution du genre Homo. PhD thesis, Muséum national d'Histoire naturelle, Paris, France

Balzeau A, Gilissen E, Wendelen W, Coudyzer W (2009) Internal cranial anatomy of the type specimen of Pan paniscus and available data for study. Journal of Human Evolution 56: 205-208

Balzeau A, Gilissen E (2010) Endocranial shape asymmetries in Pan paniscus, Pan troglodytes and Gorilla gorilla assessed via skull based landmark analysis. Journal of Human Evolution 59: 54-69

Balzeau A, Grimaud-Hervé D, Gilissen E (2011) Where are inion and endinion? Variations of the exo- and endocranial morphology of the occipital bone during hominin evolution. Journal of Human Evolution 61:488-502

Balzeau A, Gilissen E, Grimaud-Hervé D (2012) Shared pattern of quantified endocranial shape asymmetries among anatomically modern humans, great apes and fossil hominins. PLoS One 7(1):e29581

Balzeau A, Charlier P (2016) What do cranial bones of LB1 tell us about Homo floresiensis? Journal of Human Evolution 93:12-24

Balzeau A, Buck LT, Albessard L et al (2017) The internal cranial anatomy of the Middle Pleistocene Broken Hill 1 cranium. PaleoAnthropology 2017:107-138

Balzeau A, Albessard-Ball L, Kubicka AM (2020) Variation and correlations in departures from symmetry of brain torque, humeral morphology and handedness in an archaeological sample of Homo sapiens. Symmetry 12:10.3390/sym1203043

Beaudet A, Bruner E (2017) A frontal lobe surface analysis in three archaic African human fossils: $\mathrm{OH}$ 9, Buia, and Bodo. Comptes Redus Palevol 16:499-507

Belaldavar C, Kotrashetti VS, Hallikerimath SR et al (2014) Assessment of frontal sinus dimensions to determine sexual dimorphism among Indian adults. Journal of Forensic Dental Sciences 6(1):25-30

Blaney SPA (1986) An allometric study of the frontal sinus in Gorilla, Pan and Pongo. Folia Primatologica 47(2-3):81-96

Blaney SPA (1990) Why paranasal sinuses? Journal of Laryngology and Otology 104:690-693

Bookstein F, Schafer K, Prossinger H et al (1999) Comparing frontal cranial profiles in archaic and modern Homo by morphometric analysis. Anatomical Record 257:217-224

Brothwell DR, Molleson T, Metreweli C (1968) Radiological aspects of normal variation in earlier skeletons: an exploratory study. Pergammon Press, Oxford

Buck LT, Stock JT, Foley RA (2010) Levels of intraspecific variation within the catarrhine skeleton. International Journal of Primatology 31:779-795 
Buck LT (2014) Craniofacial morphology, adaptation and paranasal pneumatisation in Late Pleistocene hominins. PhD thesis University of Roehampton

Buck LT, Stringer CB, MacLarnon AM et al (2019) Variation in paranasal pneumatisation between Mid-Late Pleistocene hominins. Bulletins et Mémoires de la Société d'Anthropologie de Paris 31:14-33

Buckland-Wright JC (1970) A radiographic examination of frontal sinuses in early British populations. Man 5:512-517

Butaric LN, Maddux SD (2016) Morphological covariation between the maxillary sinus and midfacial skeleton among sub-Saharan and circumpolar modern humans. American Journal of Physical Anthropology 160:483-497

Butaric LN, Buck LT, Balzeau A et al (in press). The paranasal sinuses of the Hofmeyr skull. In: Grine FE (ed) Hofmeyr: a Late Pleistocene human skull from South Africa. Springer, Cham

Caves AJE, Haines RW (1940) The paranasal sinuses of the anthropoid apes. Journal of Anatomy 74:493-523

Caves AJE (1961) The frontal sinus of the Gorilla. Proceedings of the Zoological Society of London 136:359-373

Chalk JR, Ross CF, Strait DS et al (2011) A finite element analysis of masticatory stress hypotheses. American Journal of Physical Anthropology 145(1):1-10

Churchill SE (1998) Cold adaptation, heterochrony and Neandertals. Evolutionary Anthropology 7:46-60

Coon CS (1962) The Origin of Races. Alfred A. Knopf, New York

Copes LE (2012) Comparative and Experimental Investigations of Cranial Robusticity in Mid-Pleistocene Hominins. PhD Dissertation, Anthropology, Arizona State University

Cvrček J, Rmoutilová R, Čechová M et al (2020) Biological relationships and frontal sinus similarity in skeletal remains with known genealogical data. Journal of Anatomy 237:798-809

Daniels DL, Mafee MF, Smith MM et al (2003) The frontal sinus drainage pathway and related structures. American Journal of Neuroradiology 24(8):1618-1627

Endo B (1965) Distribution of stress and strain produced by the masticatory force. The Journal of the Anthropological Society of Tokyo 73:123-136

Flanigan P, Kshettry VR, Mullin JP et al (2016) Frontal sinus morphometry in relation to surgically relevant landmarks in the United States population. World Neurosurgery 91:12-15

Gadekar NB, Kotrashetti VS, Hosmani J et al (2019) Forensic application of frontal sinus measurement among the Indian population. Journal of Oral and Maxillofacial Pathology 23:147-151

Gould SJ, Lewontin RC (1979) The spandrels of San Marco and the Panglossian paradigm: a critique of the adaptationist programme. Proceedings of the Royal Society of London B 205:581-598

Grubbs FE (1969) Procedures for detecting outlying observations in samples. Technometrics 11:1-21

Hammer O, Harper DAT, Ryan PD (2001) PAST: Palaeontological statistics software package for education and data analysis. Palaeontoligia Electronica 1(4):9

Hanson CL, Owsley DW (1980) Frontal sinus size in Eskimo populations. American Journal of Physical Anthropology 53: 251-255
Heuzé Y, Balzeau A (2014) Asymmetry of the mid-facial skeleton of eastern lowland gorillas (Gorilla beringei graueri) and potential association with frontal lobe asymmetries. Journal of Human Evolution 74:123-129

Holloway RL, De La Coste-Lareymondie MC (1982) Brain endocast asymmetry in pongids and hominids: Some preliminary findings on the paleontology of cerebral dominance. American Journal of Physical Anthropology 58:101-110

Holton N, Yokley T, Butaric L (2013) The morphological interaction between the nasal cavity and maxillary sinuses in living humans. Anatomical Record 296:414-426

Howell HP (1917) Voice production form the standpoint of the laryngologist. Annals of Otology, Rhinology and Laryngology 26:643-655

Keir J (2009) Why do we have paranasal sinuses? The Journal of Laryngology and Otology 123:4-8

Kim D, Lee U, Park S et al (2013) Identification using frontal sinus by three-dimensional reconstruction from computed tomography. Journal of Forensic Sciences 58:5-12

Koertvelyessy T (1972) Relationships between frontal sinus and climatic conditions - a skeletal approach to cold adaptation. American Journal of Physical Anthropology 37:161-172

Koppe T, Rae TC, Swindler DR (1999) Influence of craniofacial morphology on primate paranasal pneumatization. Annals of Anatomy 181:77-80

Kumar AP, Doggalli N, Patil K (2018) Frontal sinus as a tool in identification. International Journal of Forensic Odontology 3: $55-58$

Kupczik K, Dobson CA, Crompton RH et al (2009) Masticatory loading and bone adaptation in the supraorbital torus of developing macaques. American Journal of Physical Anthropology 139:193-203

Lund VJ (1988) The maxillary sinus in the higher primates. Acta Oto-Laryngologica 105:163-171

Maddux SD, Butaric LN (2017) Zygomaticomaxillary morphology and maxillary sinus form and function: How spatial constraints influence pneumatization patterns among modern humans. Anatomical Record 300:209-225

Marquez S (2008) The paranasal sinuses: the last frontier in craniofacial biology. Anatomical Record 261:1350-1361

Miller RL, Kahn JS (1962) Statistical Analysis in the Geological Sciences. John Wiley \& Sons, New York

Moss ML, Young RW (1960) Functional approach to craniology. American Journal of Physical Anthropology 18:281-292

Negus VE (1954) The function of the paranasal sinuses. Acta Oto-Laryngologica 44:408-426

Nethan ST, Sinha S, Chandra S (2018) Frontal sinus dimensions: An aid in gender determination. Acta Scientific Dental Sciences 2: 2-6

Neubauer S, Gunz P, Scott NA et al (2020) Evolution of brain lateralization: A shared hominid pattern of endocranial asymmetry is much more variable in humans than in great apes. Science Advances 6:eaax9935

Nikam SS, Gadgil RM, Bhoosreddy AR et al (2015) Personal identification in forensic science using uniqueness of radiographic image of frontal sinus. Journal of Forensic Odontostomatology $33: 1-7$ 
O'Higgins P, Bastir M, Kupczik K (2006) Shaping the human face. International Congress Series 1296:55-73

Palmer AR (1994) Fluctuating asymmetry analyses: A primer. In: Markow TA (ed) Developmental Instability: Its Origins and Evolutionary Implications. Kluwer, Dordrecht, pp 335-364

Palmer AR, Strobeck C (2003) Fluctuating asymmetry analyses revisited. In: Polak M (ed) Developmental Instability: Causes and Consequences. Oxford University Press, pp 279-319

Pondé JM, Metzger P, Amaral G et al (2003) Anatomic variations of the frontal sinus. Minimally Invasive Neurosurgery 46:29-32

Preuschoft H, Witte H, Witzel U (2002) Pneumatized spaces, sinuses and spongy bones in the skulls of primates. Annals of Anatomy 60:67-79

Prossinger H, Bookstein F, Schäfer K et al (2000) Reemerging stress: Supraorbital torus morphology in the mid-sagittal plane? Anatomical Record 261(5):170-172

Prossinger H, Seidler H, Wicke L et al (2003) Electronic removal of encrustations inside the Steinheim cranium reveals paranasal sinus features and deformations, and provides a revised endocranial volume estimate. Anatomical Record 273B:132-142

R Core Team (2014) R: A language and environment for statistical computing. R Foundation for Statistical Computing, Vienna [http://www.R-project.org]

Rae TC (1999) The maxillary sinus in primate paleontology and systematics. In: Koppe T, Naga H, Alt KW (eds) The paranasal sinuses of higher primates. Quintessence Books Co. Inc., Chicago, pp 177-189

Rae TC (2008) Paranasal pneumatization in extant and fossil Cercopithecoidea. Journal of Human Evolution 54:279-286

Rae TC, Koppe T (2000) Isometric scaling of maxillary sinus volume in hominoids. Journal of Human Evolution 38:411423

Rae TC, Koppe T (2004) Holes in the head: evolutionary interpretations of the paranasal sinuses in catarrhines. Evolutionary Anthropology 13(6):211-223

Rae TC, Koppe T (2008) Independence of Biomechanical Forces and Craniofacial Pneumatization in Cebus. Anatomical record 291:1414-1419

Rae TC, Koppe T, Stringer CB (2011a) The Neanderthal face is not cold adapted. Journal of Human Evolution 60(2):234-239

Rae TC, Koppe T, Stringer CB (2011b) Hyperpneumatized Neanderthals? Reply to Holton et al. (2011). Journal of Human Evolution 61(5):628-629

Rennie CO, Haffajee MR, Satyapal KS (2017) Development of the paranasal air sinuses in a South African population utilizing three dimensional (3D) reconstructed models. European Journal of Anatomy 21:197-209

Rhŷs Evans P (1992) The paranasal sinuses and other enigmas: an aquatic evolutionary theory. The Journal of Laryngology and Otology 106:214-225

Rice WR (1989) Analyzing tables of statistical tests. Evolution 43: 223-225

Ross CF, Metzger KA(2004) Bone strain gradients and optimization in vertebrate skulls. Annals of Anatomy 186:387-396

Sardi ML, Joosten GG, Pandiani CD et al (2018) Frontal sinus ontogeny and covariation with bone structures in a modern human population. Journal of Morphology 2018:1-12
Pereira-Pedro AS, Masters M, Bruner E (2017) Shape analysis of spatial relationships between orbito-ocular and endocranial structures in modern humans and fossil hominids. Journal of Anatomy 231:947-960

Seidler H, Falk D, Stringer C et al (1997) A comparative study of stereolithographically modelled skulls of Petralona and Broken Hill: Implications for future studies of middle Pleistocene hominid evolution. Journal of Human Evolution 33:691-703

Shea BT (1977) Eskimo craniofacial morphology, cold stress and maxillary sinus. American Journal of Physical Anthropology 47: 289-300

Shea BT (1983) Paedomorphosis and neoteny in the pygmy chimpanzee. Science 222(4623):521-522

Shibata S, Takemoto H (2001) Observation of the three-dimensional morphology of the frontal sinus in Pan troglodytes. Primate Research 17:1-11

Shireen A, Goel S, Ahmed IM et al (2019) Radiomorphometric evaluation of the frontal sinus in relation to age and gender in Saudi population. Journal of International Society of Preventive and Community Dentistry 9(6):584-596

Smith RJ (2009) Use and misuse of the reduced major axis for line-fitting. American Journal of Physical Anthropology 140: 476-486

Sokal RR, Braumann CA (1980) Significance tests for coefficients of variation and variability profiles. Systematic Zoology 29:50-66

Sokal RR, Rohlf FJ (1995) Biometry. Freeman, New York

Soman BA, Sujatha GP, Lingappa A (2016) Morphometric evaluation of the frontal sinus in relation to age and gender in subjects residing Davangere, Karnataka. Journal of Forensic Dental Sciences 8:57

Tang JP, Hu DY, Jiang FH et al (2009) Assessing forensic applications of the frontal sinus in a Chinese Han population. Forensic Science International 183:104.e1-104.e3

Tatlisumak E, Asirdizer M, Bora A et al (2016) The effects of gender and age on forensic personal identification from frontal sinus in a Turkish population. Saudi Medical Journal 38:41-47

Tillier AM (1975) Les sinus crâniens chez les hommes actuels et fossiles : essai d'interprétation. Doctorat de $3^{\mathrm{e}}$ Cycle, Université Paris VI, Paris

Tillier AM (1977) La pneumatisation du massif cranio-facial chez les hommes actuels et fossiles (suite). Bulletins et Mémoires de la Société d'anthropologie de Paris 4:287-316

Tückmantel S, Röllin A, Müller AE et al (2009) Facial correlates of frontal bone pneumatisation in strepsirrhine primates. Mammalian Biology 74:25-35

Uthman AT, Al-Rawi NH, Al-Naaimi AS et al (2010) Evaluation of frontal sinus and skull measurements using spiral CT scanning: an aid in unknown person identification. Forensic Science International 197:124.e1-124.e7

Verma S, Mahima VG, Patil K (2014) Radiomorphometric analysis of frontal sinus for sex determination. Journal of Forensic Dental Sciences 6(3):177-182

Van Valen LA (1962) Study of fluctuating asymmetry. Evolution 16:125-142

Vinyard CJ, Smith FH (1997) Morphometric relationships between the supraorbital region and frontal sinus in Melanesian crania. Homo 48:1-21 
Wolpoff MH (1999) Paleoanthropology. McGraw-Hill, New York Wood B, Lieberman DE (2001) Craniodental variation in Paranthropusboisei: a developmental and functional perspective. American Journal of Physical Anthropology 116:13-25

Zollikofer CP, Weissmann JD (2008) A morphogenetic model of cranial pneumatization based on the invasive tissue hypothesis. Anatomical Record 291:1446-1454

Zollikofer C, Ponce de León M, Schmitz R et al (2008) New insights into Mid-Late Pleistocene fossil hominin paranasal sinus morphology. Anatomical Record 291:1506-1516

\section{Appendix}
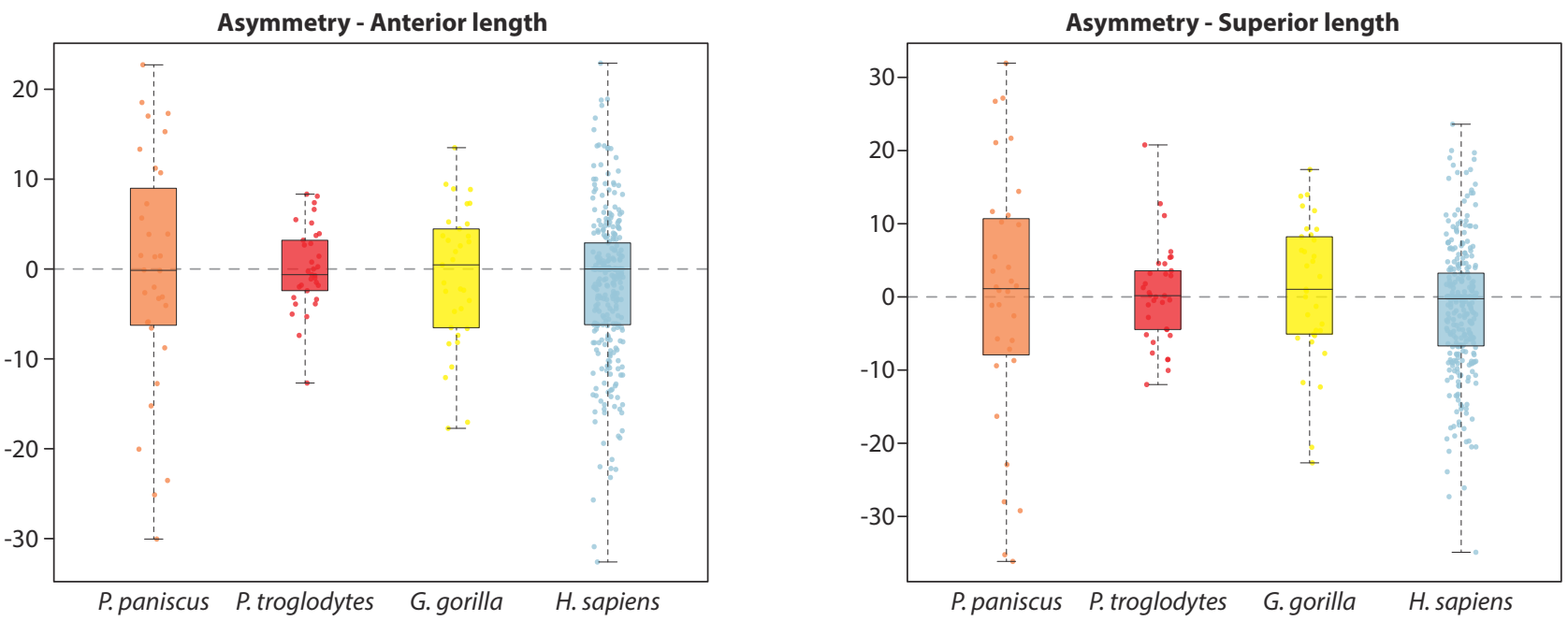

Figure S1. Boxplots of DA (= R-L) for the anterior and superior lengths of the frontal sinuses in Pan, Gorilla and Homo sapiens showing the median, inter-quartile range, the data points that are most extreme, and all data points as individual points (dots) / Boites à moustaches pour DA $(=R-L)$ des longueurs antérieure et supérieure des sinus frontaux chez Pan, Gorilla et Homo sapiens montrant la médiane, les quartiles, les points de données qui sont les plus extrêmes, et tous les points de données sous forme de points individuels (points)
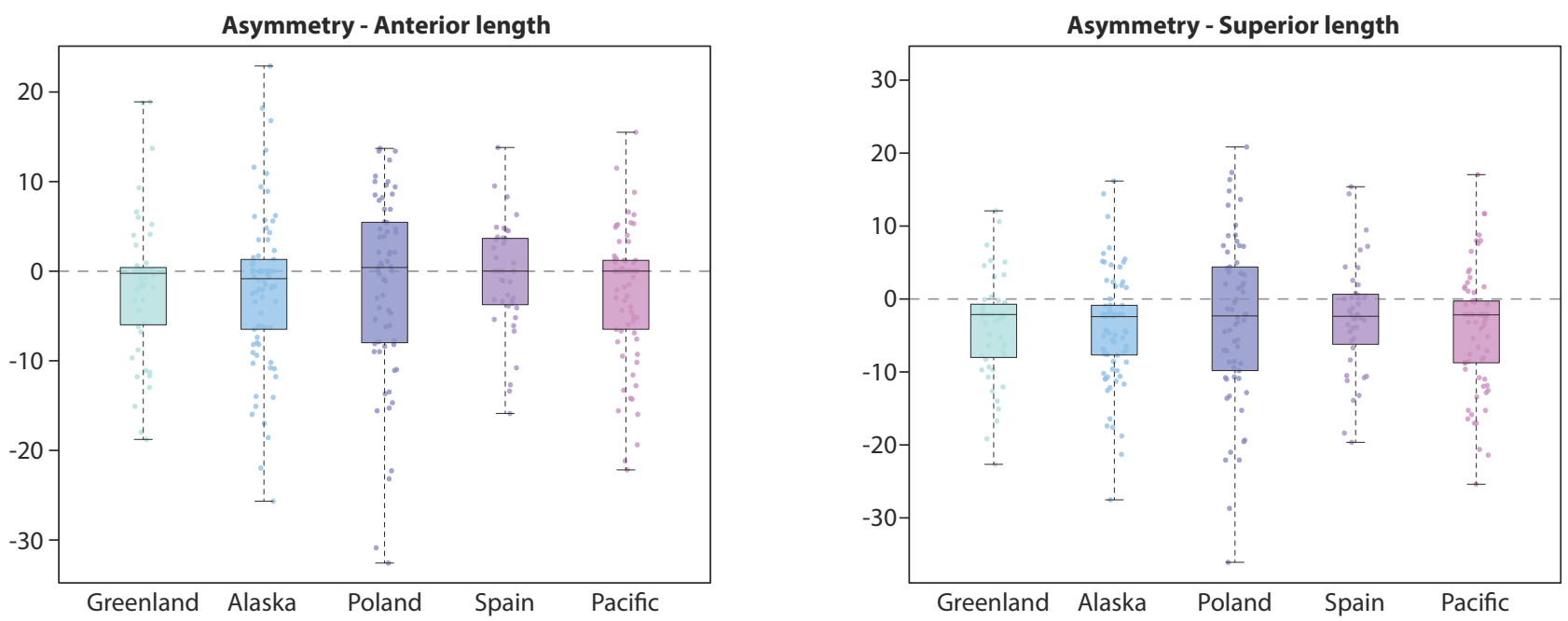

Figure S2. Boxplots of DA (= R-L) for the anterior and superior lengths of the frontal sinuses in Homo sapiens samples showing the median, inter-quartile range, the data points that are most extreme, and all data points as individual points (dots) / Boîte à moustaches pour DA $(=R-L)$ des longueurs antérieures et supérieures des sinus frontaux dans des échantillons d'Homo sapiens montrant la médiane, les quartiles, les points de données qui sont les plus extrêmes, et tous les points de données sous forme de points individuels (points) 

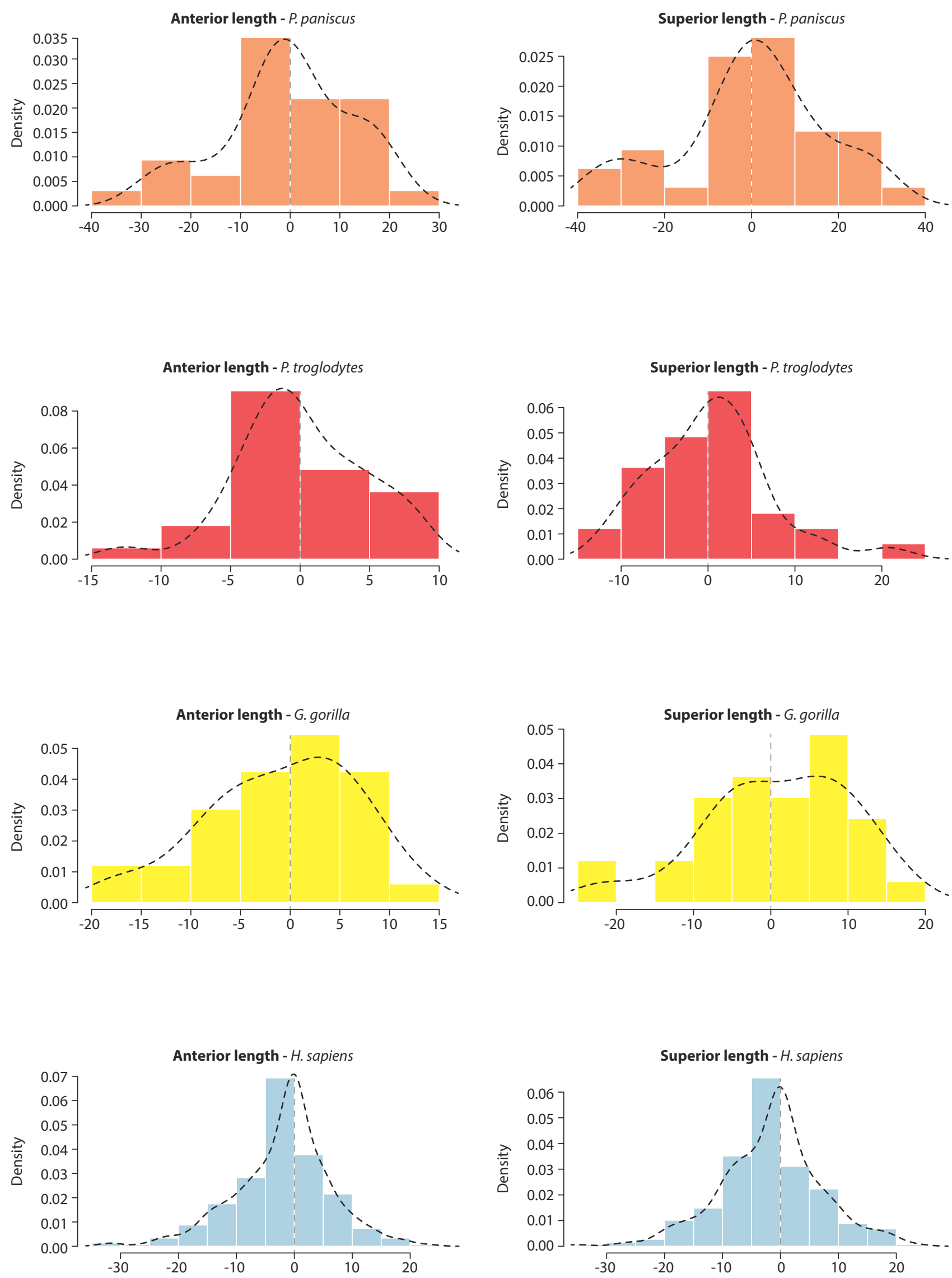

Figure S3. Density distribution of anterior and superior lengths of the frontal sinuses in Pan, Gorilla and Homo sapiens / Distribution de densité des longueurs antérieure et supérieure des sinus frontaux chez les Pan, Gorilla et Homo sapiens 
Anterior length - Greenland

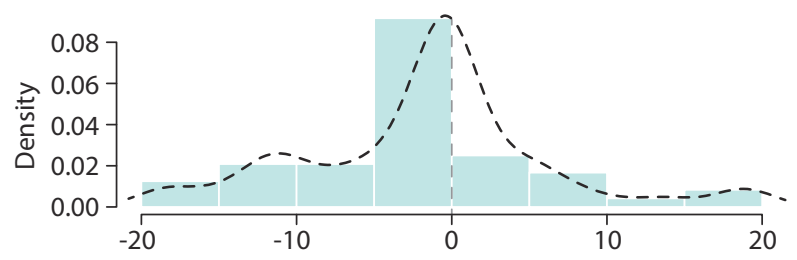

Anterior length - Alaska

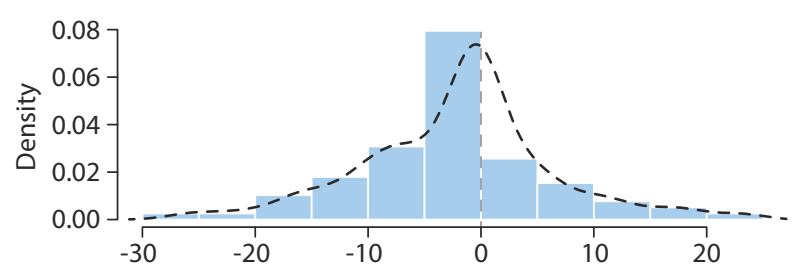

Anterior length - Poland

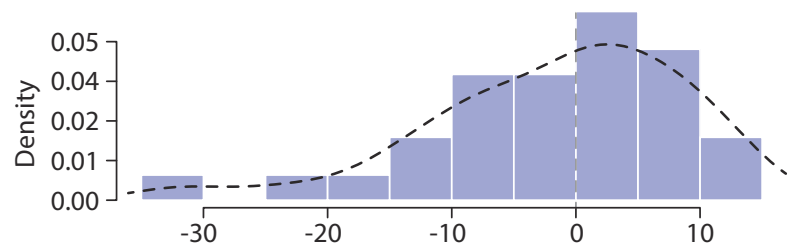

Anterior length - Spain

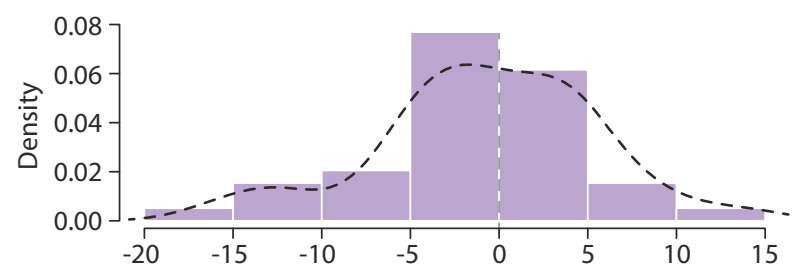

Anterior length - Pacific

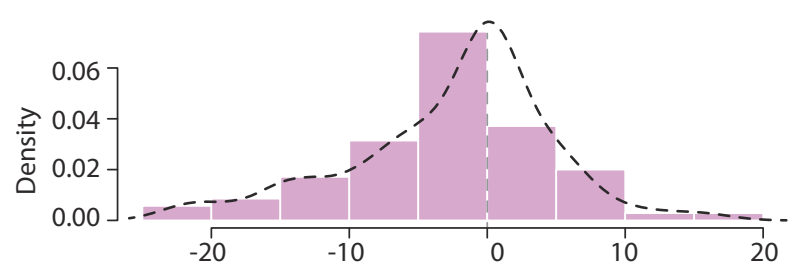

Superior length - Greenland

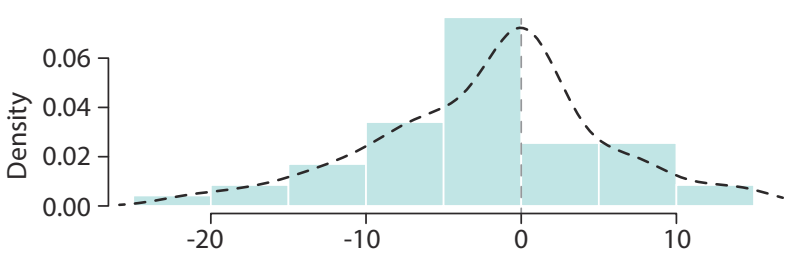

Superior length - Alaska

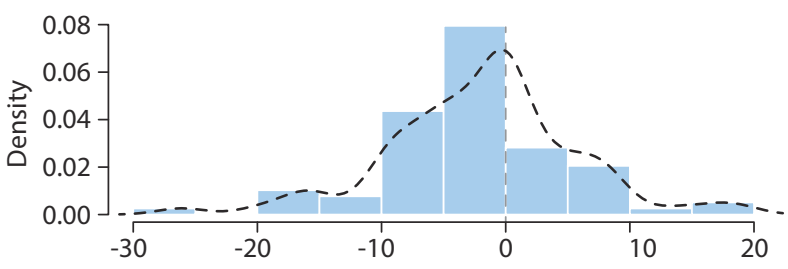

Superior length - Poland

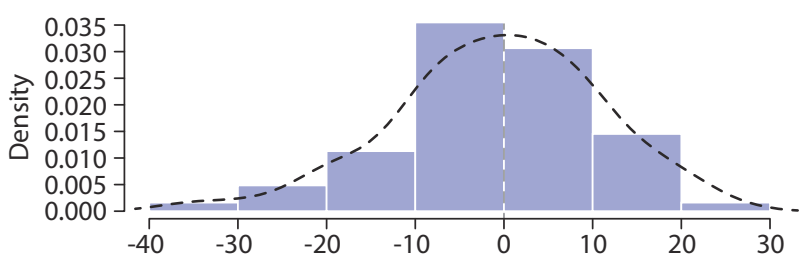

Superior length - Spain

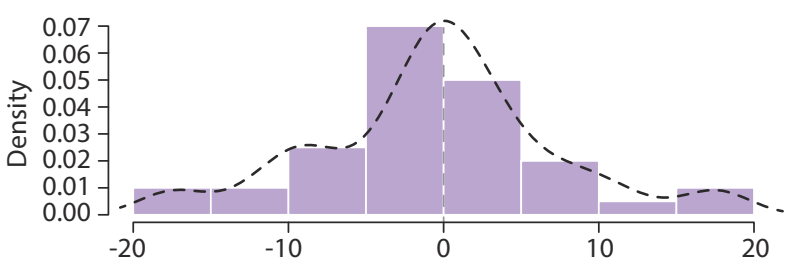

Superior length - Pacific

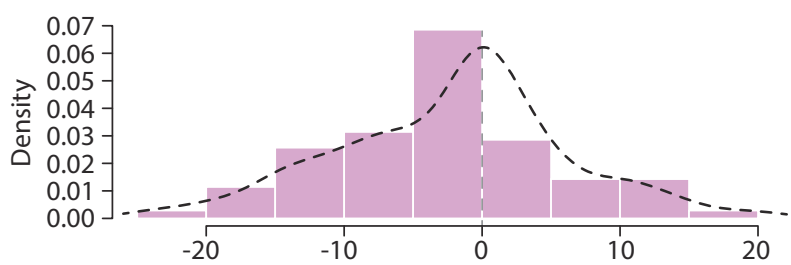

Figure S4. Density distribution of anterior and superior lengths of the frontal sinuses in Homo sapiens samples / Distribution de densité des longueurs antérieure et supérieure des sinus frontaux dans les échantillons d'Homo sapiens 